\title{
Vehicle Routing Problem for Collaborative Multidepot Petrol Replenishment under Emergency Conditions
}

\author{
Guangcan Xu $\mathbb{D}^{1}$ and Qiguang Lyu $\mathbb{D}^{2}$ \\ ${ }^{1}$ School of Economics and Management, Chongqing Jiaotong University, Chongqing 400074, China \\ ${ }^{2}$ School of Business Administration, Chongqing University of Science \& Technology, Chongqing 401331, China \\ Correspondence should be addressed to Guangcan Xu; xgc@cqjtu.edu.cn and Qiguang Lyu; lvresearch@163.com
}

Received 29 January 2021; Revised 26 March 2021; Accepted 8 April 2021; Published 19 April 2021

Academic Editor: Zheng Wang

Copyright (C 2021 Guangcan Xu and Qiguang Lyu. This is an open access article distributed under the Creative Commons Attribution License, which permits unrestricted use, distribution, and reproduction in any medium, provided the original work is properly cited.

\begin{abstract}
In recent years, emergency events have affected urban distribution with increasing frequency. For example, the 2019 novel coronavirus has caused a considerable impact on the supply guarantee of important urban production and living materials, such as petrol and daily necessities. On this basis, this study establishes a dual-objective mixed-integer linear programming model to formulate and solve the cooperative multidepot petrol emergency distribution vehicle routing optimization problem with multicompartment vehicle sharing and time window coordination. As a method to solve the model, genetic variation of multiobjective particle swarm optimization algorithm is considered. The effectiveness of the proposed method is analyzed and verified by first using a small-scale example and then investigating a regional multidepot petrol distribution network in Chongqing, China. Cooperation between petrol depots in the distribution network, customer clustering, multicompartment vehicle sharing, time window coordination, and vehicle routing optimization under partial road blocking conditions can significantly reduce the total operation cost and shorten the total delivery time. Meanwhile, usage of distribution trucks is optimized in the distribution network, that is, usage of single- and double-compartment trucks is reduced while that of three-compartment trucks is increased. This approach provides theoretical support for relevant government departments to improve the guarantee capability of important materials in emergencies and for relevant enterprises to improve the efficiency of emergency distribution.
\end{abstract}

\section{Introduction}

The collaborative multidepot petrol distribution vehicle routing problem under emergency conditions (CMPDVRPE) is an extension of the multidepot petrol station replenishment problem (MPSRP) [1]. Factors such as blocked roads under emergency conditions, cooperation among petrol depots (PDs), and distribution resources sharing are considered. CMPDVRPE optimizes vehicle routing arrangement in emergency environments through multicompartment vehicle sharing and demand time window coordination (TWC) and then reduces the total network operating cost and shortens the total delivery time. As early as 1995, multicompartment vehicle has been used to study oil distribution [2], and it is widely used in oil supply. In recent years, various emergencies, such as earthquakes and traffic accidents, have been occurring all over the world and cause road traffic blocks or closures and affect the use of several road lines. In particular, the 2019 novel coronavirus (COVID-19) outbreak in 2020 has spread around the world, causing road closures in many cities and communities and severely affecting the transportation and supply of important production and daily necessities. Such cases show the importance of the efficient and timely supply of petrol, an important material for production and daily life.

In the existing petrol distribution network, each depot is only responsible for specific petrol stations (PSs) in the region. PDs are independent of each other and lack coordination and sharing of distribution business and resources. In an emergency, roadblocks cause detours for several distribution trucks, resulting in low distribution efficiency and timeliness of the entire network. Furthermore, in such 
cases, petrol is an important and necessary material, such as the replenishment demand of vehicles for disaster relief and medical treatment, and thus, ensuring its efficient and timely supply is of considerable significance for rescue and recovery. Therefore, cooperation between regional PDs must be enhanced and the routing arrangement of distribution trucks should be optimized through resource sharing and business coordination of multidepots on the premise of partial road blocking. This cooperation can effectively reduce the operation cost of the entire petrol distribution network, improve the efficiency of emergency petrol distribution in the region, shorten the total distribution time in the region, and ensure the timely supply of important production and living materials such as petrol.

In this study, multicompartment truck sharing (TS), TWC, truck route detour, and a cooperation mechanism are integrated into the traditional MPSRP as CMPDVRPE. An optimal mathematical model is established to minimize the total operating cost and total delivery time to optimize the CMPDVRPE and get good results. An improved multiobjective particle swarm optimization (MOPSO) algorithm considering genetic variation $(\mathrm{GV})$ is designed to achieve the near-optimal solution. Correlation results before and after optimization are compared and analyzed, and the solution of CMPDVRPE can improve the efficiency and rationality of vehicle routing arrangement of petrol distribution networks. First, petrol products have special distribution natures, such as product diversification, and cannot be mixed. Second, multidepot cooperation, multicompartment vehicle use, different TWC mechanisms, and vehicle routing optimization are comprehensively considered to propel the sustainable development of vehicle routing problem (VRP) theory $[3,4]$ and emergency urban transportation system.

The remaining parts of this paper are organized as follows. In Section 2, relevant studies on petrol distribution optimization considering multidepot cooperation and vehicle routing optimization are reviewed. In Section 3, a practical example of CMPDVRPE is presented and a mathematical model is established using notations and definitions to minimize total operating costs and total delivery time. In Section 4, an improved heuristic algorithm is introduced to solve CMPDVRPE. In Section 5, a small-scale example and a case study in Chongqing City in China are conducted to verify the applicability of the proposed methodology. In Section 6, the conclusions and future directions are provided.

\section{Literature Review}

In the past few decades, relatively little research has been carried out on petrol replenishment in academic circles. Existing research focuses on the distribution of petrol in a single depot and the variations of PS replenishment problem. For example, the multiperiod, time window (TW), trip packing, and multidepot with TWS are separately considered for PSRP [1, 5-7], which with its related problems attract increasing research focus for their practical importance. Popović et al. [8] proposed a heuristic algorithm based on variable neighborhood search to solve the multiproduct and multiperiod inventory routing problem (IRP) for multicompartment homogeneous vehicles. Their method proved superior to other optimization methods. Vidović et al. [9] developed a mixed-integer programming model and a heuristic method to observe its effects on multiproduct multiperiod IRP in fuel supply. Wang et al. [10] proposed a mathematical model considering petrol trucks returning multiple times to a depot, solved using a heuristic algorithm according to a local branch-and-bound search with a Tabu list and the Metropolis acceptance criterion. Wang et al. [11] constructed an adaptive large neighborhood search (ALNS) to solve the fuel replenishment problem (FRP) and performed sensitivity analysis on different features, including the number of vehicles, products, and vehicle compartments and capacities.

The above studies directly relate to the replenishment problem of PSs. However, the models mainly considered the multicompartment vehicle transportation and time window assignment (TWA). Huang [12] proposed the Tabu search to solve an advanced capacitated location routing problem in a distribution network with multiple pickup and delivery routes. Derigs et al. [13] introduced a formal model, an integer programming formula, and reference set of 200 examples for a class of delimited general VRP with compartments and presented a set of heuristic component solvers. Lahyani et al. [14] optimized a rich multiproduct, multiperiod, and multicompartment vehicle route for the collection of olive oil in Tunisia using mathematical formulas, especially a precise branch-and-cut algorithm. Coelho and Laporte [15] defined and compared four main categories of the multicompartment delivery problem (MCDP). The study proposed formulas and models for specific MCDP cases and versions and then described a branch-and-cut algorithm that works for all variants. Ostermeier and Hübner [16] identified vehicle-related costs in empirical data collection and used a large neighborhood to solve grocery delivery for an extended multicompartment vehicle routing problem (MCVRP). Qi et al. [17] proposed a VRP method for large-scale TW based on spatiotemporal partitioning using a genetic algorithm (GA) to cluster largescale customers with K-medoid. Moreira et al. [18] presented a new method to solve the time window assignment vehicle routing problem (TWAVRP) where TWS is defined for multiple product segments. A mathematical heuristic method based on fixed optimization is used to solve the twostage stochastic optimization problem. Martins et al. [19] extended research on MCVRP by tackling a multiperiod environment with a product-oriented TWA and proposed an adaptive large neighborhood search as a solution. Eshtehadi et al. [20] studied the VRP with multicompartment vehicles operating from a single depot to visit customers within the chosen time period by minimizing major operational costs.

One part of CMPDVRPE literature focuses on the cooperation in distribution networks, which largely influences the arrangement of vehicle routes and the entire network efficiency. Wang et al. [21] established an intraregional oil distribution model with allocation quantity and route as decision variables to extend the multidepot half-open VRP 
with TWS and then used GA as a solution. Wang et al. [22] used a mixed-integer linear programming model to minimize the total operating cost of the nonempty two-echelon heterogeneous cooperative logistics network alliance and the GA-particle swarm optimization (PSO) algorithm to reallocate customer clustering units. Wang et al. [23] established a biobjective programming model to optimize the total operation routing cost and the total number of delivery vehicles for collaborative multidepot VRP with TWA (CMDVRPTWA). The model was solved using a hybrid heuristic algorithm consisting of $\mathrm{K}$-means clustering, Clark-Wright (CW) saving algorithm, and an extended nondominated sorting genetic algorithm-II (E-NSGA-II).

Another part of the CMPDVRPE literature focuses on the VRP in emergency distributions. Sheu [24] presented a hybrid fuzzy clustering-optimization approach to the emergency logistics codistribution response to the urgent relief demands in the crucial rescue period. Zhang and Xiong [25] studied the routing optimization problem of grain emergency vehicle scheduling with three objectives and presented a hybrid algorithm as a solution based on combining artificial immune and ant colony optimization (ACO) algorithms. Huizing et al. [26] described a mixed-integer linear program and several increasingly refined heuristics for the optimization problem of timetabling jobs and moving responders over a discrete network. A large set of benchmark instances, both from real-life case study data and from a generator, was created for the study.

Generally speaking, the mathematical model of VRP is hard NP, which requires solutions using appropriate algorithms. Kuo et al. [27] proposed a hybrid PSO with GA (HPSOGA) for solving capacitated VRP with fuzzy demand (CVRPFD). Wang et al. [28] minimized the total cost of the two-echelon logistics distribution network using a hybrid extended PSO and GA (EPSO-GA), which combines the merits of global and local search capabilities. Zhou et al. [29] proposed two partheno GA (PGA) and adapted PSO and one state-of-the-art method to solve the multiple traveling salesman problem (MTSP).

The above studies tackle plentiful MPSRP aspects but suffer from the following issues. (1) The vehicle routing optimized design procedure rarely considers the cooperation among PDs by regional partitioning. (2) Minimal attention is paid to distribution TS, multicompartment truck application, roadblocks, and transship transportation in a collaborative multidepot optimization network. (3) Single intelligent algorithm and heuristic approach are difficult to apply directly to a specific scale of CMPDVRPE with numerous PSs.

Combining observations in Table 1 , the main contributions of the present study lie in the following aspects. (1) A cooperation mechanism is proposed based on the regional partitioning method and a collaborative multidepot PS replenishment VRP with emergency conditions is constructed. (2) A mixed-integer linear programming model is established on the basis of the minimum total operating cost and total delivery time for CMPDVRPE. (3) An improved MOPSO algorithm is designed to effectively address the optimization model. (4) Finally, a small-scale example and a real-world case study are used to assess the applicability of the proposed model and approach and then compare the costs and delivery time before and after the vehicle routing optimization. In addition, this study lays a foundation and strategy for optimizing the VRP in emergencies and is conducive to improving its application range.

\section{Problem Statement and Model Formulation}

3.1. Problem Statement. CMPDVRPE integrates the problems of cooperative VRP, TS, roadblocks, and TWAs. Figure 1 illustrates a noncooperative petrol distribution network in which PDs operate independently and serve only their own customers. Roads blocked in an emergency can severely affect the timely supply of petrol. As such, long-haul deliveries are inevitable. A single PD also needs a large number of delivery petrol tankers to meet the different demands and TW requirements of its customers. This case results in a substantial decrease in distribution efficiency and increase in distribution costs. Given the numerous crosstransportations, delivery times dramatically increase and cannot be controlled.

Figure 2 displays an optimized petrol distribution network with cooperation, vehicle routing optimization, roadblocks, TS, and TWAs. In this network, large tankers transfer petrol across depots and are responsible for petrol delivery to many or a single PS. This cooperation leads to more efficient and reasonable distribution routes than the noncooperative distribution network. The delivery times, required number of petrol distribution trucks, and service scope of each PD are likewise reduced.

Based on the regional partitioning method, the transport time between PDs and stations is used to cluster corresponding PSs. Then appropriate distribution trucks are selected and distribution routes are arranged according to the demand of different petrol, demand TW, and roadblocks to each PS.

Seven assumptions underline the corresponding mathematical model. (1) In a relatively short working period, each PS only generates one distribution order for petrol demand. For each kind of petrol, the demand does not exceed the maximum loading capacity of most distribution truck compartments. (2) Each customer (PS) can only be served once in a working period, that is, only one distribution truck is used for its delivery service. (3) The petrol transfer and distribution trucks have constant transportation speed. (4) During a working period, distribution trucks may be dispatched repeatedly if time permits, regardless of the transfer time across PDs. (5) The loading and unloading service times of PDs and stations are related not to the petrol type but to the truck type and operational quantity. (6) Every 10 minutes is the time unit. (7) No consideration is given to the restriction of road geometry on multicompartment vehicles.

3.2. Model Formulation. The proposed model is mathematically formulated as an optimization problem to minimize the total cost and delivery time when each PD is assigned to serve a group of PSs and VRP with different 
TABLE 1: Comparison between existing literature and the present study.

\begin{tabular}{lcccccc}
\hline Study & Regional partitioning & Stations per trip & Time windows & Multicompartment & Fleet sharing & Emergency conditions \\
\hline Cornillier et al. [1] & No & Several & Yes & Yes & No & No \\
Govindan et al. [30] & No & Several & Yes & No & No & No \\
Lahyani et al. [14] & No & Several & No & Yes & No & No \\
Wang et al. [28] & No & Several & Yes & No & No & Yes \\
Zhang et al. [25] & No & Several & No & Yes & No & No \\
Wang et al. [31] & No & Several & No & Yes & Yes & No \\
Xu et al. [32] & Yes & One & Yes & Yes & Yes & Yes \\
This study & Yes & Several & Yes & & &
\end{tabular}

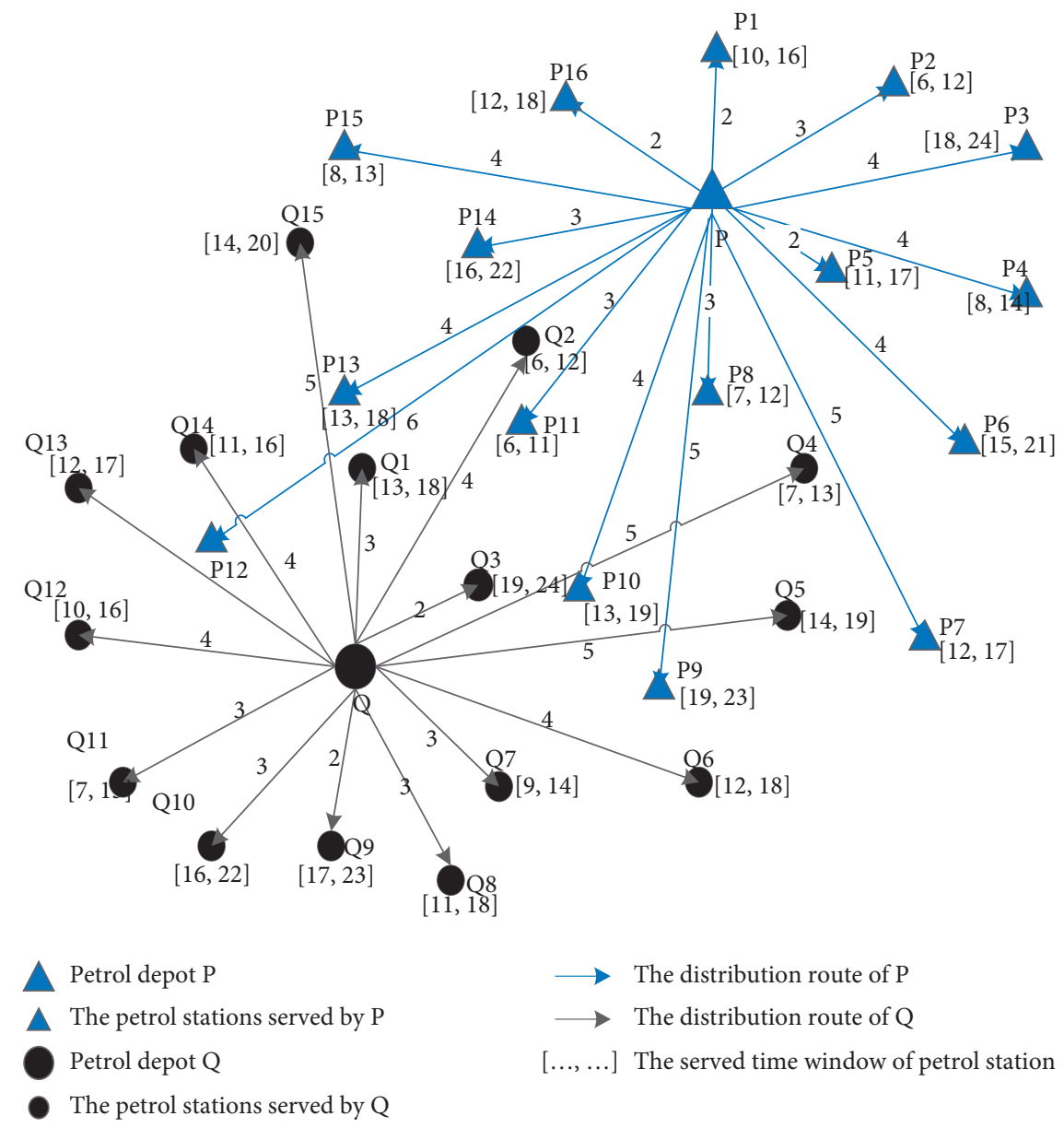

Figure 1: Noncooperative petrol distribution network.

trucks and TWS [20,33]. Tables 2 and 3 list the related notations and definitions in the CMPDVRPE optimization and the judgement variables, respectively.

CMPDVRPE is formulated as a mixed-integer linear programming model to minimize the total cost and delivery time. The cost function contains four components, namely, $C_{1}, C_{2}, C_{3}$, and $C_{4}$, which are described below.

Equation (1) shows the formulation for $C_{1}$, which denotes the transport cost of tankers that transfer petrol between PDs during a working period:

$$
C_{1}=\sum_{g, h \in D} \sum_{o \in O} \sum_{p \in P}\left(f_{o} \times P_{F} \times t_{g h}^{D} \times x_{g h o}^{p}\right) .
$$

Equation (2) shows the formulation for $C_{2}$, which denotes the transportation costs of petrol distribution trucks during a working period, including transportation costs from the PD to the PS and from PS to PS:

$$
C_{2}=\sum_{i \in D \cup S} \sum_{j \in S} \sum_{k \in K}\left(f_{k} \times P_{F} \times t_{i j}^{D \cup S} \times x_{i j k}\right) .
$$




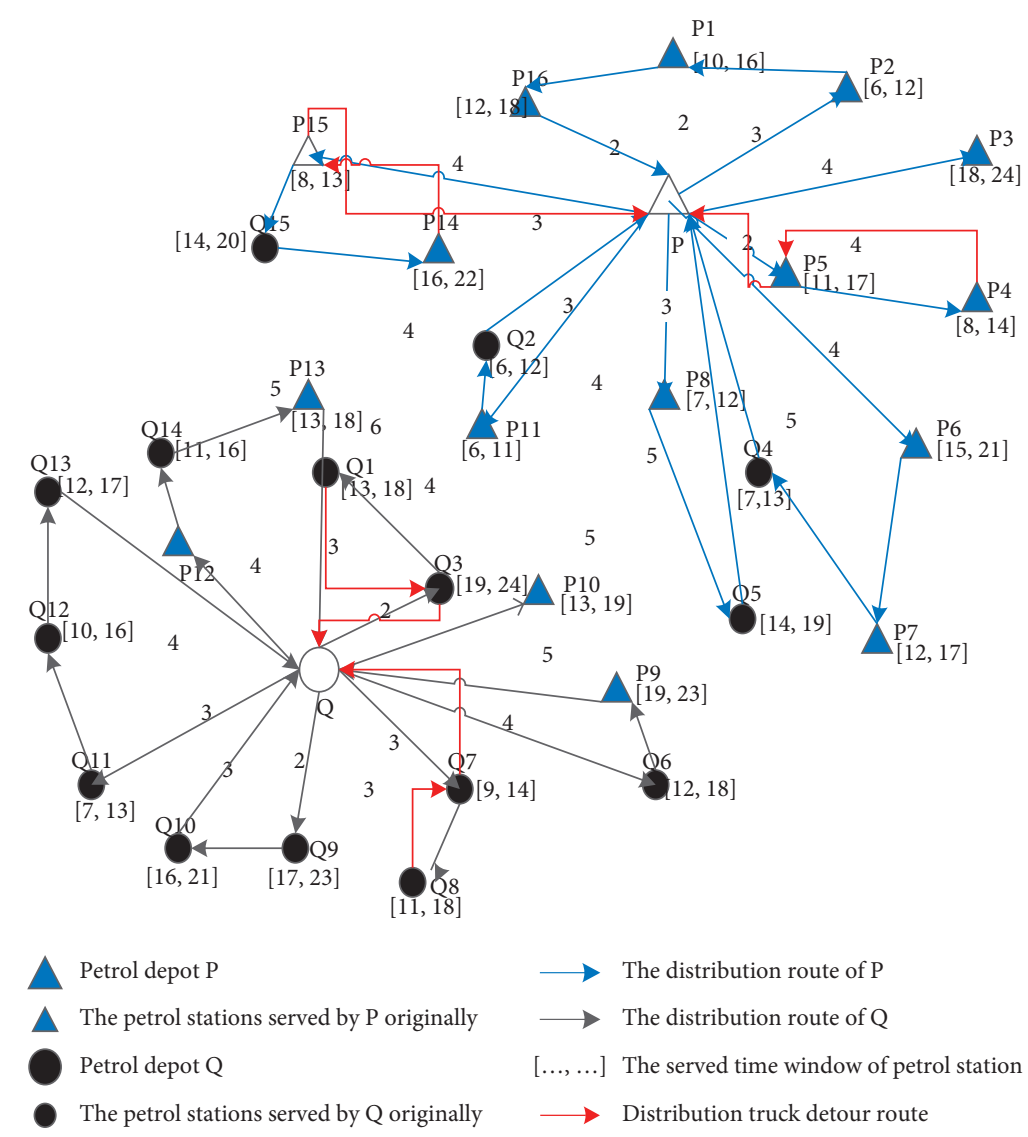

FIGURE 2: Cooperative petrol distribution network.

Equation (3) shows the formulation for $C_{3}$, which denotes the penalty cost of the distribution truck arriving early or late at the PS, that is, the impact of the distribution truck arrival time on the cost under the premise of fixed service TW at the PS:

$$
C_{3}=\sum_{i \in D \cup S} \sum_{j \in S} \sum_{k \in K} x_{i j k} \times \mu_{e} \times\left[\max \left\{\alpha_{j}-t r_{j k}, 0\right\}\right]+\sum_{i \in D \cup S} \sum_{j \in S} \sum_{k \in K}\left[\max \left\{t r_{j k}-\beta_{j}\right\}\right] .
$$

Equation (4) shows the formulation for $C_{4}$, which denotes the maintenance cost of all petrol tankers in a working period, and the fixed cost of the PD after considering the incentive of the government competent authority or leader of the cooperative alliance:

$$
C_{4}=\sum_{g, h \in D} \sum_{o \in O} \sum_{p \in P}\left(\frac{x d_{g h o}^{p} \times q_{g h p}}{Q^{o}} \times \frac{M_{o}}{N_{w}}\right)+\sum_{i \in D} \sum_{j \in J} \sum_{k \in K}\left(x_{i j k} \times \frac{M_{k}}{N_{w}}\right) .
$$

The optimization model of CMPDVRPE is defined as follows:

$$
\begin{aligned}
& \min T C_{1}=C_{1}+C_{2}+C_{3}+C_{4}, \\
& \min T C_{2}=\sum_{k \in K} \sum_{i \in D \cup S} \sum_{j \in S} t_{i j k},
\end{aligned}
$$

subject to

$$
\begin{gathered}
\sum_{i \in D \cup S} \sum_{j \in S} x_{i j k} \leq 1, \quad \forall k \in K, \\
\sum_{j \in D \cup S} x_{i j k}-\sum_{j \in D \cup S} x_{j i k}=0, \quad \forall i \in D \cup S, \forall k \in K,
\end{gathered}
$$


TABLE 2: Notations and definitions in CMPDVRPE.

\begin{tabular}{|c|c|}
\hline Symbol & Description \\
\hline$D$ & Set of petrol depot, $i \in D$ \\
\hline$S$ & Set of petrol station, $j \in S$ \\
\hline$P$ & Set of petrol, $p \in P$ \\
\hline$O$ & Set of petrol tanker, $o \in O$ \\
\hline$K$ & Set of petrol distribution truck, $k \in K$ \\
\hline$f_{o}$ & Fuel consumption per time unit of a petrol tanker, $o \in O$ \\
\hline$f_{k}$ & Fuel consumption per time unit of petrol distribution truck, $k \in K$ \\
\hline$P_{F}$ & Fuel price \\
\hline$Q^{o}$ & Loading capacity of petrol tanker, $o \in O$ \\
\hline$Q^{k}$ & The loading capacity of single compartment of truck $k, k \in K$ \\
\hline$t_{g h}^{D}$ & The transport time from petrol depot $\mathrm{g}$ to $h, g, h \in D$ \\
\hline $\begin{array}{l}t_{i j}^{D N u S} \\
{\left[m_{i}, n_{i}\right]}\end{array}$ & $\begin{array}{c}\text { The transport time from the depot to the petrol station or from the petrol station to another, } i \in D \cup S, j \in S \\
\text { The working hours of petrol depot } i, i \in D\end{array}$ \\
\hline$\left[\alpha_{i}, \beta_{j}\right]$ & The service time window of petrol station, $j \in J$ \\
\hline$t_{i k}$ & The departure time of distribution truck $k$ from petrol depot $i, i \in D, k \in K$ \\
\hline$t r_{i k}$ & The time of distribution truck $k$ returning to the petrol depot $i$ or arriving at the petrol station $i, i \in D \cup S, k \in K$ \\
\hline$t_{i j k}$ & The driving time of distribution truck $k$ from petrol depot $i$ to petrol station $j$ or petrol station $i$ to $j, i \in D \cup S, j \in S, k \in K$ \\
\hline $\mathrm{T}$ & The maximum travel time allowed for each distribution truck \\
\hline$\mu_{e}$ & The penalty cost per unit of time for distribution trucks arriving early \\
\hline$\mu_{d}$ & The penalty cost per unit of time for distribution trucks arriving late \\
\hline$M_{o}$ & The annual maintenance cost of a petrol tanker, $o \in O$ \\
\hline$M_{k}$ & The annual maintenance cost of distribution truck $k, k \in K$ \\
\hline$q_{g h p}$ & During a working period, the amount of petrol $p$ is transferred from depot $g$ to $h, g, h \in D, p \in P$ \\
\hline$q_{j p}$ & During a working period, the demand of petrol station $j$ for petrol $p, j \in J, p \in P$ \\
\hline$q_{j}^{k p}$ & During a working period, the amount of petrol $p$ delivered to the petrol station $j$ by the distribution truck $k, j \in S, k \in K, p \in P$ \\
\hline$C^{k p}$ & Integer variable, the number of compartments of distribution truck $k$ loaded with petrol $p, k \in K, p \in P$ \\
\hline$Q_{d}$ & Service capacity of depot $d$ during a working period, $d \in D$ \\
\hline$F I_{i}$ & $\begin{array}{l}\text { The fixed cost of petrol depot } i \text { in a working period, that is, when the petrol depot } i \text { joins the cooperative network, the fixed cost can } \\
\text { be covered by the rewards given to the partners by the government authorities or the cooperative alliance leaders, } i \in D\end{array}$ \\
\hline$N_{i}$ & The number of distribution trucks at petrol depot $i$ serving petrol stations during a working period, $i \in D$ \\
\hline$N_{k}$ & The number of compartments for distribution trucks, $k \in K$ \\
\hline$N_{w}$ & The number of working periods per year \\
\hline
\end{tabular}

TABLE 3: Judgement variables.

\begin{tabular}{|c|c|c|}
\hline $\begin{array}{l}\text { Decision } \\
\text { variables }\end{array}$ & \multicolumn{2}{|r|}{ Definition } \\
\hline$x_{i j k}$ & \multicolumn{2}{|c|}{ When the distribution truck $k$ serving route $(i, j)$, the variable value is 1 ; otherwise, it is $0, i \in D \cup S, j \in S, k$} \\
\hline$x d_{g h o}^{p}$ & \multicolumn{2}{|c|}{$\begin{array}{l}\text { When the petrol tanker } o \text { transfers the petrol } p \text { from the petrol depot } g \text { to } h \text {, the variable is } 1 \text {; otherwise, it } \\
\qquad g, h \in D, o \in O, p \in P\end{array}$} \\
\hline$y_{j}^{k}$ & \multirow{2}{*}{\multicolumn{2}{|c|}{$\begin{array}{l}\text { When the petrol station } j \text { is visited by the distribution truck } k \text {, the variable is } 1 \text {; otherwise, it is } 0, j \in J, k \\
\text { When the distribution truck } k \text { starts from the petrol depot } d \text { and passes through the route }(i, j) \text {, the variable } \\
\text { otherwise, it is } 0, d \in D, i, j \in S, k \in K\end{array}$}} \\
\hline$\omega_{i j k d}$ & & \\
\hline$r_{g j h}$ & \multicolumn{2}{|c|}{$\begin{array}{l}\text { When the serving petrol depot of petrol station } j \text { is adjusted from } g \text { to } h \text { after the petrol distribution netw } \\
\text { optimization, the variable is } 1 \text {; otherwise, it is } 0, g, h \in D, j \in S\end{array}$} \\
\hline $\mathrm{CO}_{i}$ & \multicolumn{2}{|c|}{ When depot $i$ agrees to join the cooperative petrol distribution network, the variable is 1 ; otherwise, it is 0 , } \\
\hline & $\sum_{p \in P} C^{k p} \leq N_{k}, \quad \forall k \in K$ & $\sum_{j \in S} q_{j}^{k p} \leq C^{k p} Q^{k}, \quad \forall k \in K, p \in P$ \\
\hline & $0 \leq C^{k p} \leq N_{k}, \quad \forall k \in K, p \in P$ & $0 \leq q_{j}^{k p} \leq \min \left\{Q^{k} N_{k}, q_{j p}\right\}, \quad \forall j \in S, k \in K, p \in P$, \\
\hline & $\sum_{k \in K} y_{j}^{k} q_{j}^{k p}=q_{j p}, \quad \forall j \in S, p \in P$ & $\sum_{p \in P} \sum_{k \in K} y_{j}^{k} q_{j}^{k p}=\sum_{p \in P} q_{j p}, \quad \forall j \in S$ \\
\hline & $q_{j}^{k p} \leq y_{j}^{k} Q^{k} N_{k}$ & $\sum_{j \in S} \sum_{p \in P} y_{j}^{k} q_{j}^{k p} \leq Q^{k} N_{k}, \quad \forall k \in K$ \\
\hline
\end{tabular}




$$
\begin{gathered}
\sum_{g, h \in D} \sum_{p \in P} x d_{g h o}^{p} q_{g h p} \leq Q^{o}, \quad \forall o \in O, \\
q_{g h p}=\sum_{j \in S} r_{g j h} q_{j p}, \quad \forall g, h \in D, p \in P, \\
m \leq t_{i k} \leq n, \quad \forall i \in D, \forall k \in K, \\
m \leq t r_{i k} \leq n, \quad \forall i \in D, k \in K, \\
\sum_{i \in D \cup S} \sum_{j \in S} t_{i j k} \leq T, \quad \forall k \in K, \\
t_{i k}+t_{i j k}=t r_{j k}, \quad \forall i \in D \cup S, \forall j \in S, \forall k \in K, \\
\alpha_{j} \leq t r_{j k} \leq \beta_{j}, \quad \forall j \in S, \forall k \in K, \\
\sum_{i, j \in s} x_{i j k} \leq|s|-1, \quad \forall s \subset S,|s| \geq 2, \forall k \in K, \\
\omega_{i j k d}=\{0,1\}, \quad \forall d \in D, \forall i, j \in S, i \neq j, \forall k \in K, \\
x_{i j k}=\{0,1\}, \quad \forall i \in D \cup S, \forall j \in S, \forall k \in K, \\
=\{0,1\}, \quad \forall g, h \in D, \forall o \in O, \forall p \in P, \\
y_{g h o}=\{0,1\}, \quad \forall j \in S, \forall k \in K,
\end{gathered}
$$

Equations 5 and (6) show the objective functions that minimize the total cost and total delivery time of the regional petrol distribution network, respectively. Constraint (7) stipulates that each distribution truck is required to serve at most one PD and one distribution route. Constraint (8) ensures flow conservation. Constraint (9) ensures that only one kind of petrol can be loaded into each distribution truck compartment, that is, the petrol cannot be mixed. Constraint (10) ensures that the number of compartments of the distribution truck $k$ loaded with petrol $p$ is less than the total number of compartments. Constraint (11) indicates that the total amount of all distribution trucks that deliver to PS $j$ is equal to the station demand for petrol $p$. Constraint (12) ensures that the amount of petrol $p$ distributed by the distribution truck $k$ to PS $j$ is not greater than the total truckload. Constraint (13) ensures that the distribution truck does not deliver more petrol $p$ than it loads. Constraint (14) indicates that the amount of petrol $p$ delivered by the distribution truck to PS $j$ should not be greater than the smaller value between its maximum loading and the demand of the PS $j$ for petrol $p$. Constraint (15) ensures that the PS demand for a product can only be delivered by one distribution truck. Constraint (16) stipulates that the distribution truck $k$ is required to deliver no more petrol than its total loading capacity to all the stations visited. Constraint (17) ensures that the amount of petrol transferred between depots is not greater than the loading capacity of tankers. Constraint (18) indicates that the amount of petrol $p$ transferred from PD $g$ to $h$ is equal to the demand for $p$ from the newly added service stations after optimization of the cooperative network. Constraints (19) and (21) specify the service time of the PD and the maximum duration constraint of the distribution truck travel. Constraints (22) and (23) constrain the time of distribution truck serving PS. Constraint (24) represents the elimination of subloop constraints. Equations (25) and (30) are judgement and decision variables.

\section{Solution Methodology}

4.1. PSO. As a method of evolutionary computing, PSO was proposed in 1995 by Eberhart, an American electrical engineer, and Kenndey, a social psychologist. By observing the foraging behavior of birds, the authors believed that at first, the birds do not know where the food but come closer and closer to the food through a kind of information exchange. This information includes the adaptability of each bird to estimate its own position according to certain rules, ability of each bird to remember its best position, and the best position found by all the birds in the flock. The best position found by the bird group is called individual optimal "pbest," while the best position found by the whole bird group is called global optimal "gbest" [34].

In PSO, the entire population is called particle swarm, and each individual in the population is called a particle. The target is a search space, and the position of each particle is a potentially feasible solution. Each particle in space adjusts its flight path based on personal and group experience to find the optimal solution.

Suppose the population is composed of $n$ particles, and in a $D$-dimensional target search space, each particle can be regarded as a point in space, then $x_{i}=\left\{x_{i 1}, x_{i 2}, \ldots, x_{i D}\right\}$ represents the $D$-dimensional vector of particle $i(i=1,2, \ldots, m)$. A particle flies in space at a certain speed, as $v_{i}=\left\{v_{i 1}, v_{i 2}, \ldots, v_{i D}\right\}$. Generally, the fitness represented by the objective function is used to calculate the current particle fitness value, to judge the advantages and disadvantages of the particle position. The local optimal particle position is pbest $=\left\{\right.$ pbest $_{i 1}$, pbest $_{i 2}, \ldots$, pbest $\left._{i D}\right\}$. At the same time, the best adaptive value experienced by the entire particle swarm is the global optimal value, gbest $=\left\{\right.$ gbest $_{i 1} ;$ gbest $_{i 2}, \ldots$, gbest $\left._{i D}\right\}$. The particle optimizes the search process iteratively, and for each of its generation, the $d(1 \leq d \leq D)$ dimensional position and velocity are updated by the following equation iteration [34]:

$$
\begin{aligned}
v_{i d}(t+1)= & v_{i d}(t)+c_{1} r_{1}\left(\text { pbest }_{i d}(t)-x_{i d}(t)\right) \\
& +c_{2} r_{2}\left(\text { gbest }_{i d}(t)-x_{i d}(t)\right) \\
x_{i d}(t+1)= & x_{i d}(t)+v_{i d}(t+1)
\end{aligned}
$$

where $c_{1}, c_{2}$ are the learning coefficients, also known as the acceleration coefficients, and $r_{1}, r_{2}=\operatorname{ran} d[0,1]$, namely, $r_{1}, r_{2}$ are the random numbers between 0 and 1 . 
4.2. MOPSO. The single-objective optimization problem only needs to obtain a single or a set of continuous optimal solutions, while the multiobjective optimization problem generally obtains a set of continuous solutions. For the basic PSO, all particles converge in one direction following the best particle (leader), and thus, the single-objective optimization problem can be solved. When solving the multiobjective optimization problem, pbest (individual optimal solution) and gbest (globally optimal solution) cannot be directly determined due to the lack of a single optimal solution, and thus, the basic PSO method cannot be directly adopted.

In fact, the solution of the multiobjective optimization problem is composed of a set of noninferior solutions. Different particles seek different "leaders" in the optimization. The noninferior solutions are stored in the "external container" (archive). Furthermore, by evaluating the "quality" of these solutions, the gbest is determined to realize the guidance of particle iterative updating. Clearly, the archived solution can represent the optimal subset of particles that the algorithm finds in each generation of particle swarm, and thus, considering the archived set as a candidate set for the gbest is appropriate [35].

MOPSO is a cyclic process. When the algorithm starts, the first-generation noninferior solution is found from the initialized particle swarm and stored in the external archive. Subsequently, the gbest is selected from the external container by comparison, and then, the particle swarm updates the speed and position through equations (31) and (32). Then, the loop operation is repeated.

Based on the generation of new nondominant solutions after each particle iteration, the external archive set size, and thereby the computation, increases after multiple iterations. Therefore, considering the effect of computational complexity, limiting the size of external collections is necessary [35]. Once the number of solutions in the external archive collection reaches the upper limit set for the external container, the noninferior solutions in the external container are compared and a few are deleted according to certain rules.

In solving MOPSO, the evaluation criteria of particles, construction, and preservation of noninferior solutions, selection of optimal positions, and the processing of constraints are mainly used.

4.3. IMOPSO. PSO is characterized by rapid convergence speed, but for a multiobjective optimization problem, too fast convergence speed may cause particles to fall into the local optimal. Thus, achieving the global optimal becomes difficult. This problem may be prevented by introducing the mutation operation of particles.

In the early stage of the algorithm, the particle needs to search the entire target space to ensure the escape from the local optimal state and enhance the global search capability; in the late stage, a quick convergence is necessary to find the optimal solution. Thus, this study carries out mutation operation on particles through mutation probability. At the beginning of the algorithm, mutation should be carried out on all particles, and with the increase of iteration, the number of particles undergoing mutation should be gradually reduced. According to the variation operation requirements, the variation probability of particle swarm after each update is set as follows [36]:

$$
m p=1-\frac{P_{i t}}{\max _{i t}},
$$

where $m p$ is the mutation probability, $P_{i t}$ is the current iterations, and $\max _{i t}$ is the maximum number of iterations. In reference to the nonuniform mutation operator in the GA, a random variable rand between 0 and 1 is assigned to each particle. If the random variable of particle $i$ is less than the probability of variation, then random nonuniform variation operation is carried out on the $D$-dimensional particle position:

$$
x_{i d}= \begin{cases}x_{i d}+\lambda \times v_{i d} \times\left(1-\operatorname{rand}_{i}\right), & \operatorname{rand}_{i} p 0.5 ., \\ x_{i d}-\lambda \times v_{i d} \times\left(1-\operatorname{rand}_{i}\right), & \operatorname{rand}_{i} \geq 0.5 .\end{cases}
$$

In equation (34), $\lambda$ is the system random parameter $(\lambda>1)$. During the variation operation, if the result is greater than the threshold set by the system, the variation result is set at the boundary of the threshold range.

In addition, to balance the global and local search capability of basic PSO, adding inertia weight is necessary [37], that is, the influence of inertia weight coefficient is considered when updating the velocity of particles. Therefore, the new velocity updating formula of particles is as follows:

$$
\begin{aligned}
v_{i d}(t+1)= & \omega v_{i d}(t)+c_{1} r_{1}\left(p_{i d}(t)-x_{i d}(t)\right) \\
& +c_{2} r_{2}\left(g_{i d}(t)-x_{i d}(t)\right) .
\end{aligned}
$$

Combined with the basic PSO algorithm and MOPSO, Figure 3 describes the procedure of the IMOPSO algorithm. The steps of the MOPSO algorithm considering GV are as follows:

(1) Initialization: set the particle swarm size, parameter coefficient, threshold, maximum number of iterations, and initial velocity and initial position of each particle.

(2) Use equations (33) and (34) to carry out variation on particle swarm.

(3) Calculate the fitness value of each particle.

(4) Construct the set of noninferior solutions of particle swarm according to the construction algorithm of noninferior solutions.

(5) Update the pbest of each particle according to Pareto dominance concept.

(6) Update the external archive set according to the saving algorithm of noninferior solution.

(7) Calculate the crowding distance of particles in the external archive. If the number of particles entering the external archive reaches the upper limit of the external archive size, the particles beyond the upper limit of the external archive size are removed in ascending crowding distance order. 


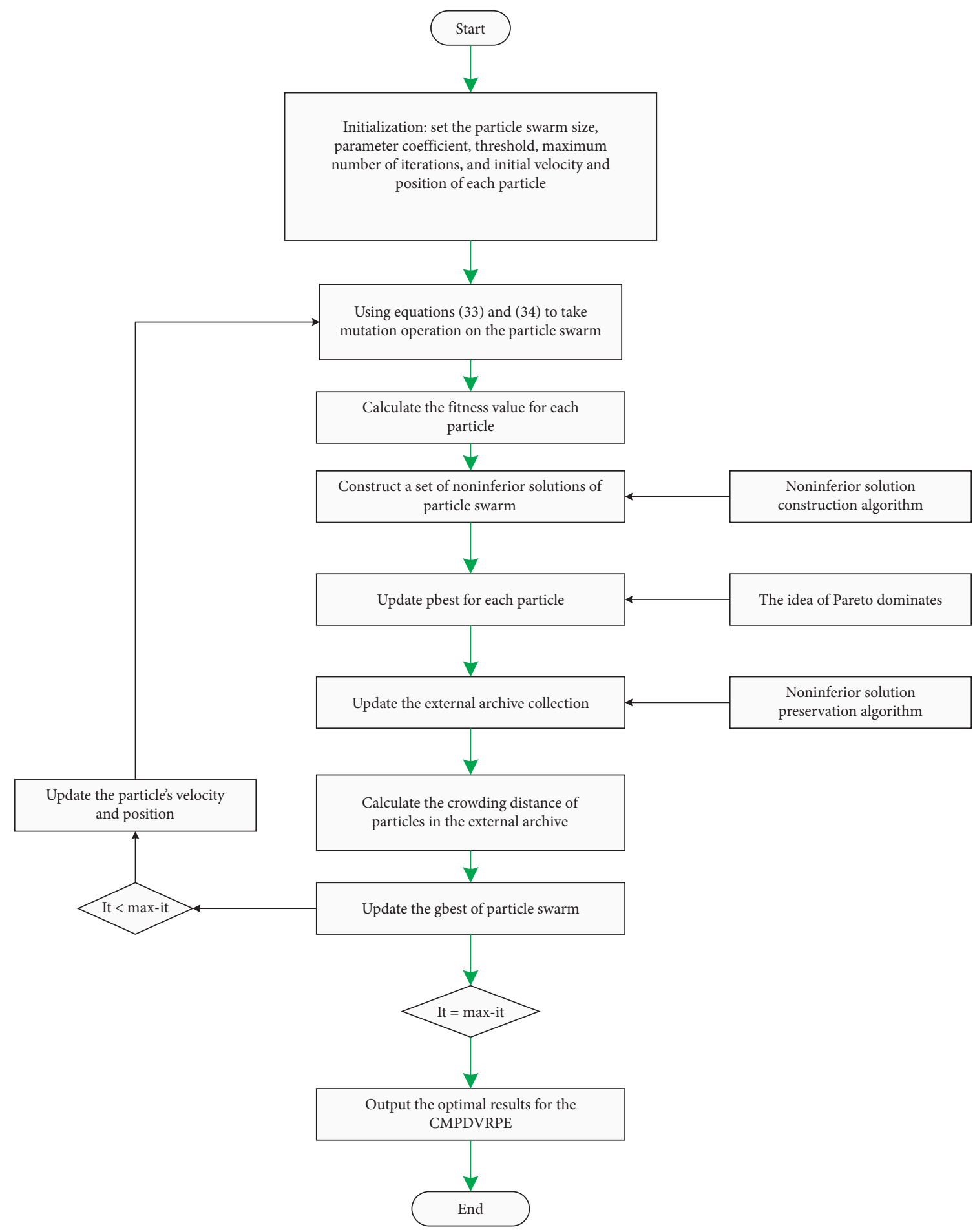

FIGURE 3: Flowchart of the IMOPSO algorithm.

(8) Update the gbest of particle swarm. In the external archive, the front-end particles in descending order of crowding distance are randomly selected as the gbest.

(9) Update the particle velocity and position according to equations (31) and (32), and return to step (2). When the maximum number of iterations is reached, the loop is terminated.

\section{Case Study}

5.1. Small-Scale Example. The quality of the proposed heuristic algorithm in solving the problem of multidepot vehicle routing with emergency effects is further demonstrated by a small example analysis. In this case, the petrol distribution network consists of two PDs and 31 PSs in the region. Under noncooperation, $\mathrm{PD} P$ is responsible for $\mathrm{P} 1$, 
$\mathrm{P} 2, \ldots, \mathrm{P} 16$ and other 16 PSs petrol distribution, while $\mathrm{PD} Q$ is responsible for Q1, Q2, .., Q15 and other 15 PSs petrol distribution. With cooperation according to the customer clustering and the distance between each PS and the PD, the PSs distributed by the two PDs are first repartitioned. In addition, distribution routes are blocked under emergency control. Then, the two PDs can share the petrol distribution trucks. The customers and routes of the distribution truck can be decided according to the demand TW, demand characteristics (including petrol products and quantity demand), and transportation distance and detour route of each petrol station in one distribution task, as shown in Figure 2.

For the convenience of calculation, the following assumption is made for this example: the demand of petrol product of PSs is divided into three categories, namely, nos. 92, 95, and 98. The distribution trucks have three types: single compartment with a capacity of 2,000 gallons, double compartment with a capacity of 1,500 gallons, and three compartments with a capacity of 1,500 gallons. Each time unit represents 10 minutes, and the transportation cost per unit time is $\$ 50$ for a single-compartment truck, $\$ 70$ for a double-compartment truck, and $\$ 80$ for a three-compartment truck. The fixed cost of single-compartment truck, double-compartment truck, and three-compartment truck is $\$ 20, \$ 30$, and $\$ 40$, respectively. In addition, considering the customer demand TW, the penalty cost of the distribution truck arriving early per unit time is $\$ 10$, and the penalty cost of the distribution truck arriving late per unit time is $\$ 15$. The single assignment cost of the distribution truck is \$20. For example, the vehicle route $\mathrm{P} \longrightarrow \mathrm{Q} 4 \longrightarrow \mathrm{P} 7 \longrightarrow$ $\mathrm{P} 6 \longrightarrow \mathrm{P}$ uses a three-compartment vehicle, the entire route vehicle needs to run 11 time units, transportation cost is $\$ 880$, fixed cost is $\$ 40$, and the vehicle assignment cost is $\$ 20$. According to (5), the total cost of the route is $\$ 1,160$.

Table 4 shows that compared with the condition of noncooperation, the cooperative multidepot petrol distribution network has a significant decrease in the delivery time, number of distribution trucks, transportation cost, and total cost. Total delivery time under the cooperative condition dropped to 1080 minutes, which was $52 \%$ lower than that under the noncooperative condition. With cooperation, the number of trucks required for distribution and use of single- and double-compartment trucks considerably decreased whereas the use of three-compartment trucks increased to a certain extent. Overall, the number of needed distribution trucks declined from 31 to 14 , fixed cost declined from $\$ 1470$ to $\$ 760$, and transportation cost declined from $\$ 15,180$ to $\$ 7,800$. In the case of joint distribution, the integrated use of trucks and the reasonable arrangement of vehicle routes need consideration, resulting in a penalty cost of $\$ 350$ for trucks arriving early or being late. In general, with cooperation, the total cost of dual depots petrol distribution network is $\$ 8,910$, which is significantly reduced by $46 \%$ compared with the noncooperative condition. In addition, IMOPSO performed 30 random operations, with the optimal result on the $23 \mathrm{rd}$. The results show that considering TS and route optimization, the petrol distribution network can achieve significant cost savings, considerably reduce the total delivery time, and significantly reduce the number of distribution trucks. Table 4 also reveals two interesting phenomena. First, the cooperative distribution network considerably reduced the use of single- and double-compartment trucks and increased the use of three-compartment trucks. This finding indicates that the use of distribution trucks is coordinated through the integration of customer requirements, and multiple PSs can be served by sending one distribution truck at a time. Second, the penalty cost has increased because the joint distribution comprehensively considers the customer TW and truck route arrangement and the detour of trucks under emergency road blocking. In certain cases, trucks arrive early or late, but the overall delivery time is reduced and the benefits are optimized. Of course, attention should also be paid to the impact of early or late arrival on customer satisfaction.

5.2. Large-Scale Example. In this section, a numerical experiment is applied to a large-scale multidepot petrol distribution network in Chongqing, China. The urban petrol distribution network in Chongqing municipality, which is directly under the jurisdiction of western China, is selected as the experimental object to demonstrate the effectiveness of IMOPSO in solving the vehicle routing optimization for the emergency joint distribution of multidepot. In this case, the petrol distribution network consists of five PDs (PD1, PD2, .., PD5) and 86 PSs (PS1, PS2, .., PS86). Figure 4 shows the distribution of all PDs and PSs, and each PS has a fixed demand TW. Specifically, PD1 serves the PSs represented by the circle, PD2 serves the PSs represented by the rectangle, PD3 serves the PSs represented by the triangle, PD4 serves the PSs represented by the cross, and PD5 serves the PSs represented by the hexagon. Table 5 shows PSs initially served by different PDs.

As mentioned in the previous Section 3.2, the optimization objective is to minimize the total cost and time of the distribution network through the cooperation of different PDs, customer clustering, TW coordination, integration of distribution trucks, and vehicle route optimization under emergency road blocking. In this numerical experiment, a petrol tanker with a loading capacity of 5,000 gallons was selected, and the distribution trucks were single-compartment $k 1$, double-compartment $k 2$, and three-compartment $k 3$. Relevant parameter values of the optimization model and its algorithm are adopted from the literature $[11,23,33]$ as follows: $f_{o}=8, f_{k 1}=5, f_{k 2}=6, f_{k 3}=7, P_{F}=6, Q^{o}=5000$, $Q^{k 1}=2000, \quad Q^{k 2}=1500, \quad Q^{k 3}=1500, \quad \mu_{e}=3, \quad \mu_{d}=5$, $M_{o}=5000, \quad M_{k 1}=3700, \quad M_{k 2}=4100, \quad M_{k 3}=4500$, $F I_{1}=1300, \quad F I_{2}=1300, \quad F I_{3}=1500, \quad F I_{4}=1000$, $F I_{5}=1200$, population pop-size $=500$, learning factor $c_{1}=c_{2}=2$, maximum iteration number $\max -i t=100$, and inertia weight $i w=0.9$. In addition, the service time of PD is from 6:00 to 24:00. Table 6 shows the service TW of PS while Table 7 shows the demand for different petrol products of each station in the working period.

In this study, a working period can be regarded as a working day. Based on the participation of different cooperation subjects, five PDs can have $2^{5}-1$ different 
TABle 4: Comparison of relative indexes of multidepot petrol distribution network in a small-scale example.

\begin{tabular}{|c|c|c|c|c|c|c|c|c|}
\hline \multirow[b]{2}{*}{ Condition } & \multirow{2}{*}{$\begin{array}{c}\text { Total delivery } \\
\text { time } \\
\text { (minutes) }\end{array}$} & \multicolumn{3}{|c|}{ Number of trucks required for distribution } & \multirow{2}{*}{$\begin{array}{l}\text { Fixed } \\
\text { cost } \\
\text { (USD) }\end{array}$} & \multirow[b]{2}{*}{$\begin{array}{l}\text { Transportation } \\
\text { cost (USD) }\end{array}$} & \multirow{2}{*}{$\begin{array}{c}\text { Penalty } \\
\text { cost } \\
\text { (USD) }\end{array}$} & \multirow{2}{*}{$\begin{array}{c}\text { Total } \\
\text { cost } \\
\text { (USD) }\end{array}$} \\
\hline & & $\begin{array}{c}\text { Single- } \\
\text { compartment }\end{array}$ & $\begin{array}{c}\text { Double- } \\
\text { compartment }\end{array}$ & $\begin{array}{c}\text { Three- } \\
\text { compartment }\end{array}$ & & & & \\
\hline Noncooperative & 2240 & 12 & 15 & 4 & 1470 & 15180 & - & 16650 \\
\hline Cooperative & 1080 & 2 & 4 & 8 & 760 & 7800 & 350 & 8910 \\
\hline
\end{tabular}

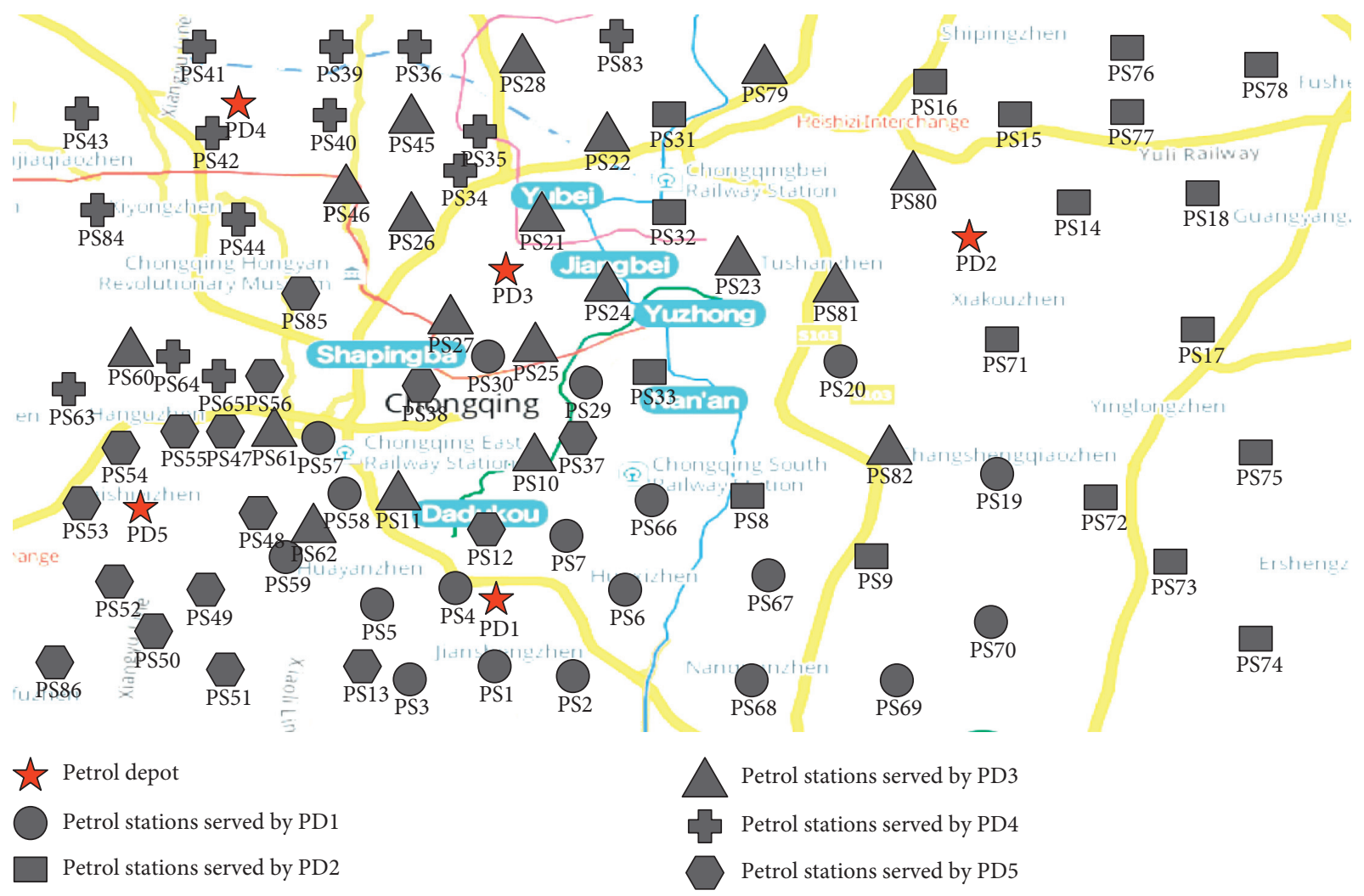

FIGURE 4: Distribution network diagram of multidepot and multistation.

TABLE 5: PSs served by different PDs before optimization.

\begin{tabular}{lc}
\hline PD & PS \\
\hline PD1 & PS1 PS2 PS3 PS4 PS5 PS6 PS7 PS19 PS20 PS29 PS30 PS57 PS58 PS59 PS66 PS67 PS68 PS69 PS70 \\
PD2 & PS8 PS9 PS14 PS15 PS16 PS17 PS18 PS31 PS32 PS33 PS71 PS72 PS73 PS74 PS75 PS76 PS77 PS78 \\
PD3 & PS10 PS11 PS21 PS22 PS23 PS24 PS25 PS26 PS27 PS28 PS45 PS46 PS60 PS61 PS62 PS79 PS80 PS81 PS82 \\
PD4 & PS34 PS35 PS36 PS39 PS40 PS41 PS42 PS43 PS44 PS63 PS64 PS65 PS83 PS84 \\
PD5 & PS12 PS13 PS37 PS38 PS47 PS48 PS49 PS50 PS51 PS52 PS53 PS54 PS55 PS56 PS85 PS86 \\
\hline
\end{tabular}

cooperation alliances. First, the PSs that are responsible for distribution in each PD are reallocated through a clustering algorithm, and then the assignment and route optimization of distribution trucks are calculated using the IMOPSO algorithm. Thus, the optimized distribution cost, delivery time, and the number of different distribution trucks used per time in a working period are obtained. For the convenience of comparison and analysis, Table 8 and Figure 5 show the cost optimization results of the different cooperative alliances.
Figure 5 shows that the total operating cost of all alliances decreased compared with that of individual PD. In particular, when all PDs are willing to cooperate and a grand alliance can be formed, the reduction in operating costs is significant even if local truck detours are caused by emergency road blocking. Compared with the initial network for the entire petrol distribution, the cost decreased by $65.59 \%$. Therefore, cooperation can benefit the operation costs reduction of multidepot petrol emergency distribution network. 
TABLE 6: TW demand of PS.

\begin{tabular}{lccccc}
\hline PS & Demand TW & PS & Demand TW & PS & Demand TW \\
\hline PS1 & {$[10,16]$} & PS30 & {$[7,13]$} & PS59 & {$[19,24]$} \\
PS2 & {$[8,14]$} & PS31 & {$[13,18]$} & PS60 & {$[17,23]$} \\
PS3 & {$[11,17]$} & PS32 & {$[10,16]$} & PS61 & {$[12,17]$} \\
PS4 & {$[16,22]$} & PS33 & {$[17,23]$} & PS62 & {$[9,14]$} \\
PS5 & {$[7,13]$} & PS34 & {$[8,14]$} & PS63 & {$[14,19]$} \\
PS6 & {$[14,20]$} & PS35 & {$[12,17]$} & PS64 & {$[13,18]$} \\
PS7 & {$[12,18]$} & PS36 & {$[15,21]$} & PS65 & {$[10,15]$} \\
PS8 & {$[10,15]$} & PS37 & {$[9,14]$} & PS66 & {$[7,12]$} \\
PS9 & {$[6,12]$} & PS38 & {$[16,22]$} & PS67 & {$[18,23]$} \\
PS10 & {$[15,21]$} & PS39 & {$[11,17]$} & PS68 & {$[6,11]$} \\
PS11 & {$[17,23]$} & PS40 & {$[14,20]$} & PS69 & {$[11,16]$} \\
PS12 & {$[9,15]$} & PS41 & {$[6,11]$} & PS70 & {$[10,15]$} \\
PS13 & {$[12,17]$} & PS42 & {$[18,24]$} & PS71 & {$[16,21]$} \\
PS14 & {$[18,24]$} & PS43 & {$[10,16]$} & PS72 & {$[15,20]$} \\
PS15 & {$[8,13]$} & PS44 & {$[8,13]$} & PS73 & {$[8,13]$} \\
PS16 & {$[16,21]$} & PS45 & {$[15,21]$} & PS74 & {$[10,16]$} \\
PS17 & {$[10,16]$} & PS46 & {$[12,18]$} & PS75 & {$[12,17]$} \\
PS18 & {$[15,20]$} & PS47 & {$[7,12]$} & PS76 & {$[19,24]$} \\
PS19 & {$[11,17]$} & PS48 & {$[19,24]$} & PS77 & {$[14,19]$} \\
PS20 & {$[17,23]$} & PS49 & {$[9,15]$} & PS78 & {$[9,15]$} \\
PS21 & {$[7,12]$} & PS50 & {$[14,20]$} & PS79 & {$[11,17]$} \\
PS22 & {$[14,19]$} & PS51 & {$[8,14]$} & PS80 & {$[16,22]$} \\
PS23 & {$[9,15]$} & PS52 & {$[18,23]$} & PS81 & {$[13,19]$} \\
PS24 & {$[17,22]$} & PS53 & {$[11,17]$} & PS82 & {$[7,13]$} \\
PS25 & {$[15,21]$} & PS54 & {$[17,23]$} & PS83 & {$[15,21]$} \\
PS26 & {$[11,16]$} & PS55 & {$[10,16]$} & PS84 & {$[10,16]$} \\
PS27 & {$[13,19]$} & PS56 & {$[12,18]$} & PS85 & {$[8,14]$} \\
PS28 & {$[19,24]$} & PS57 & {$[16,21]$} & PS86 & {$[15,20]$} \\
PS29 & {$[18,23]$} & PS58 & {$[7,13]$} & & \\
\hline & & & & &
\end{tabular}

Table 9 and Figure 6 show that the total delivery time of all alliances decreased compared with that of individual PD. In particular, when all PDs are willing to cooperate and a grand alliance can be formed, the total delivery time savings are significant even though several PSs have longer delivery times due to detours. Compared with the initial network for the entire petrol distribution, the delivery time decreased by $56.59 \%$. Therefore, the optimization of vehicle route can benefit the saving of delivery time in multidepot petrol emergency distribution network.

Table 10 shows the changes in distribution truck usage before and after optimization in different cooperative alliances, mainly including the change of demand truck type and corresponding quantity. Specifically, distribution trucks are shared through cooperation between PDs. Based on the service TW of different PSs and the quantity of petrol required, the usage and route arrangement of different truck types are reasonably planned. As a result, usage considerably decreased for single-compartment trucks $(k 1)$, decreased to a certain extent for double-compartment trucks $(k 2)$, and significantly increased for three-compartment trucks $(k 3)$. For example, for the grand alliance $\{$ PD1 PD2 PD3 PD4 $\mathrm{PD} 5\}$, usage of single-compartment trucks $(k 1)$ significantly decreased from 27 trucks to 6 trucks per time, that of doublecompartment trucks $(k 2)$ decreased from 36 to 17 trucks per time, while that of three-compartment trucks $(k 3)$ increased from 27 to 35 trucks per time. The change in the number of trucks is mainly due to the change of petrol distribution
TABLE 7: PS demand for different petrol types during a working period.

\begin{tabular}{|c|c|c|c|}
\hline \multirow{2}{*}{ PS } & \multicolumn{3}{|c|}{ Petrol demand (gallons) } \\
\hline & 92 & 95 & 98 \\
\hline PS1 & 1309 & 691 & - \\
\hline PS2 & 2781 & 933 & 422 \\
\hline PS3 & 857 & 334 & 182 \\
\hline PS4 & 1289 & - & 157 \\
\hline PS5 & 2387 & 491 & 806 \\
\hline PS6 & 2576 & 327 & 969 \\
\hline PS7 & 2891 & 383 & 262 \\
\hline PS8 & 1989 & - & - \\
\hline PS9 & 1467 & 1028 & 946 \\
\hline PS10 & 1510 & 1351 & 721 \\
\hline PS11 & 1016 & 1258 & 730 \\
\hline PS12 & 1010 & 879 & 376 \\
\hline PS13 & 1696 & 411 & 607 \\
\hline PS14 & 1557 & 1066 & 312 \\
\hline PS15 & 2335 & 1194 & 690 \\
\hline PS16 & 632 & 1137 & 691 \\
\hline PS17 & 1635 & 816 & 228 \\
\hline PS18 & 2372 & 288 & 993 \\
\hline PS19 & 694 & 658 & 949 \\
\hline PS20 & 2481 & 452 & - \\
\hline PS21 & 1570 & 1064 & 829 \\
\hline PS22 & 1736 & 752 & - \\
\hline PS23 & 1949 & 925 & 577 \\
\hline PS24 & 2774 & 1298 & 182 \\
\hline PS25 & 1783 & 1126 & 277 \\
\hline PS26 & 2935 & 907 & 667 \\
\hline PS27 & 2830 & - & 971 \\
\hline PS28 & 875 & 1383 & 214 \\
\hline PS29 & 1791 & - & 597 \\
\hline PS30 & 1967 & 794 & 154 \\
\hline PS31 & 2058 & 520 & 930 \\
\hline PS32 & 2024 & 346 & - \\
\hline PS33 & 770 & 297 & 225 \\
\hline PS34 & 927 & 322 & 651 \\
\hline PS35 & 2955 & 1060 & 727 \\
\hline PS36 & 515 & 1246 & 924 \\
\hline PS37 & 1684 & 941 & 474 \\
\hline PS38 & 1326 & 539 & 972 \\
\hline PS39 & 1672 & 839 & 694 \\
\hline PS40 & 574 & 959 & 686 \\
\hline PS41 & 680 & - & 493 \\
\hline PS42 & 982 & 478 & - \\
\hline PS43 & 1485 & 1345 & 261 \\
\hline PS44 & 1609 & 282 & 237 \\
\hline PS45 & 1931 & 1387 & 690 \\
\hline PS46 & 1887 & 1223 & 221 \\
\hline PS47 & 2260 & 1082 & 348 \\
\hline PS48 & 528 & 456 & 194 \\
\hline PS49 & 1753 & 354 & - \\
\hline PS50 & 2558 & 410 & 549 \\
\hline PS51 & 2782 & 1264 & 1000 \\
\hline PS52 & 507 & 1096 & 953 \\
\hline PS53 & 2366 & 1117 & 533 \\
\hline PS54 & 885 & - & 845 \\
\hline PS55 & 639 & 292 & - \\
\hline PS56 & 513 & - & 656 \\
\hline PS57 & 667 & - & 678 \\
\hline PS58 & 2700 & 507 & 456 \\
\hline
\end{tabular}


TABle 7: Continued.

\begin{tabular}{|c|c|c|c|}
\hline \multirow{2}{*}{ PS } & \multicolumn{3}{|c|}{ Petrol demand (gallons) } \\
\hline & 92 & 95 & 98 \\
\hline PS59 & 919 & 1330 & - \\
\hline PS60 & 962 & 1372 & 645 \\
\hline PS61 & 1105 & 830 & - \\
\hline PS62 & 997 & 1199 & 468 \\
\hline PS63 & 2431 & 874 & 967 \\
\hline PS64 & 646 & 787 & 663 \\
\hline PS65 & 2449 & - & 439 \\
\hline PS66 & 732 & 1186 & 865 \\
\hline PS67 & 2892 & 1191 & 386 \\
\hline PS68 & 2473 & 711 & 783 \\
\hline PS69 & 1801 & 740 & 464 \\
\hline PS70 & 2396 & - & 871 \\
\hline PS71 & 2428 & 879 & 223 \\
\hline PS72 & 1852 & 631 & 685 \\
\hline PS73 & 1917 & 1357 & 436 \\
\hline PS74 & 756 & 970 & 334 \\
\hline PS75 & 2244 & 926 & 674 \\
\hline PS76 & 1300 & 361 & - \\
\hline PS77 & 1028 & 717 & 942 \\
\hline PS78 & 577 & 563 & - \\
\hline PS79 & 791 & 1209 & 547 \\
\hline PS80 & 2832 & 266 & 892 \\
\hline PS81 & 640 & 1301 & 912 \\
\hline PS82 & 2084 & 683 & 387 \\
\hline PS83 & 522 & - & 619 \\
\hline PS84 & 1108 & 1202 & 430 \\
\hline PS85 & 833 & 837 & 919 \\
\hline PS86 & 2447 & 915 & 273 \\
\hline
\end{tabular}

from one-to-one assignment to the one-to-many vehicle route optimization between the $\mathrm{PD}$ and the PS to coordinate the station TW and the demand for petrol products. Thus, the use of single- and double-compartment trucks decreased and that of three-compartment trucks increased.

Figures 7 and 8 compare the use of distribution trucks $k 1$ and $k 2$ before and after optimization. After optimization, usage of both $k 1$ and $k 2$ decreased to a certain extent, while that of $k 1$ decreased more. Due to the realization of the coordination between the service TW of the PS and petrol demand, in most cases, a distribution truck from the PD has to serve multiple PSs, and thus, the use of single-compartment trucks decreased.

Figure 9 shows that, relative to the decreased usage of optimized distribution trucks $k 1$ and $k 2$, the use of distribution truck $k 3$ increased after optimization. This result is mainly due to two reasons, the demand of PSs for three types of petrol and the vast majority of distribution trucks needed to serve multiple PSs at a time.

A large petrol distribution network consisting of five PDs and 86 PSs is relatively complex. Therefore, for the optimized truck distribution routes, the distribution truck route network formed by PD3 is taken as an example, as shown in Table 11. Before cooperation, the PD was responsible for one-to-one distribution of petrol products to PSs and was only responsible for the distribution of PSs operated by itself. After cooperation, PD3 reduces the distribution of longdistance PSs through clustering, such as PS61 and PS62, and
TABLE 8: Comparison between initial and optimized network over one working period (unit: USD).

\begin{tabular}{|c|c|c|c|}
\hline Alliance & $\begin{array}{c}\text { Initial } \\
\text { cost }\end{array}$ & $\begin{array}{l}\text { Optimized } \\
\text { cost }\end{array}$ & $\begin{array}{c}\text { Cost } \\
\text { saving }\end{array}$ \\
\hline$\{\mathrm{PD} 1\}$ & 7558 & 4489 & 3069 \\
\hline$\{\mathrm{PD} 2\}$ & 7413 & 4785 & 2628 \\
\hline$\{\mathrm{PD} 3\}$ & 8437 & 5312 & 3125 \\
\hline$\{\mathrm{PD} 4\}$ & 6725 & 4153 & 2572 \\
\hline$\{$ PD5 $\}$ & 7264 & 4547 & 2717 \\
\hline$\{\mathrm{PD} 1 \mathrm{PD} 2\}$ & 14,475 & 7528 & 6947 \\
\hline$\{\mathrm{PD} 1 \mathrm{PD} 3\}$ & 14,993 & 8536 & 6457 \\
\hline$\{$ PD1 PD4 $\}$ & 13,135 & 6171 & 6964 \\
\hline$\{\mathrm{PD} 1 \mathrm{PD} 5\}$ & 13,587 & 7612 & 5975 \\
\hline$\{\mathrm{PD} 2 \mathrm{PD} 3\}$ & 14,486 & 8083 & 6403 \\
\hline$\{\mathrm{PD} 2 \mathrm{PD} 4\}$ & 13,270 & 7345 & 5925 \\
\hline$\{\mathrm{PD} 2 \mathrm{PD} 5\}$ & 13,964 & 7956 & 6008 \\
\hline$\{$ PD3 PD4 $\}$ & 13,440 & 6692 & 6748 \\
\hline$\{\mathrm{PD} 3 \mathrm{PD} 5\}$ & 14,175 & 7953 & 6222 \\
\hline$\{\mathrm{PD} 4 \mathrm{PD} 5\}$ & 12,766 & 6975 & 5791 \\
\hline$\{\mathrm{PD} 1 \mathrm{PD} 2 \mathrm{PD} 3\}$ & 21,405 & 9567 & 11,838 \\
\hline$\{\mathrm{PD} 1 \mathrm{PD} 2 \mathrm{PD} 4\}$ & 19,313 & 7646 & 11,667 \\
\hline$\{P D 1$ PD2 PD5 $\}$ & 20,725 & 8734 & 11,991 \\
\hline$\{$ PD1 PD3 PD4 $\}$ & 19,694 & 7508 & 12,186 \\
\hline$\{P D 1$ PD3 PD5 $\}$ & 20,216 & 8407 & 11,809 \\
\hline$\{\mathrm{PD} 1 \mathrm{PD} 4 \mathrm{PD} 5\}$ & 20,583 & 8505 & 12,078 \\
\hline$\{\mathrm{PD} 2 \mathrm{PD} 3 \mathrm{PD} 4\}$ & 19,997 & 8156 & 11,841 \\
\hline$\{\mathrm{PD} 2$ PD3 PD5 $\}$ & 21,034 & 9445 & 11,589 \\
\hline$\{\mathrm{PD} 2 \mathrm{PD} 4 \mathrm{PD} 5\}$ & 19,172 & 7105 & 12,067 \\
\hline$\{$ PD3 PD4 PD5 $\}$ & 20,895 & 9057 & 11,838 \\
\hline$\{\mathrm{PD} 1 \mathrm{PD} 2 \mathrm{PD} 3 \mathrm{PD} 4\}$ & 26,763 & 11,302 & 15,461 \\
\hline$\{P D 1$ PD2 PD3 PD5 $\}$ & 27,442 & 10,608 & 16,834 \\
\hline$\{\mathrm{PD} 1 \mathrm{PD} 2 \mathrm{PD} 4 \mathrm{PD} 5\}$ & 27,136 & 10,715 & 16,421 \\
\hline$\{\mathrm{PD} 1 \mathrm{PD} 3 \mathrm{PD} 4 \mathrm{PD} 5\}$ & 25,724 & 9556 & 16,168 \\
\hline$\{\mathrm{PD} 2 \mathrm{PD} 3 \mathrm{PD} 4 \mathrm{PD} 5\}$ & 26,625 & 10,234 & 16,391 \\
\hline $\begin{array}{l}\{\text { PD1 PD2 PD3 PD4 } \\
\text { PD5 }\}\end{array}$ & 33,176 & 11,415 & 21,761 \\
\hline
\end{tabular}

increases the distribution of PS31, PS32, and other PSs near the PD. Second, in most cases, a distribution truck serves multiple PSs at once. For example, in the vehicle route $\mathrm{PD} 3 \longrightarrow \mathrm{PS} 21 \longrightarrow \mathrm{PS} 22 \longrightarrow \mathrm{PS} 31 \longrightarrow \mathrm{PD} 3$, a three-compartment truck starts from PD3 in the PD and serves PS21, PS22, and PS31 at one time. In addition, considering possible road emergency blocking, detour routes for distribution trucks should be designed. In the vehicle route PD3 $\longrightarrow$ PS33 $\longrightarrow$ PS29 $\longrightarrow$ PS25 $\longrightarrow$ PS29 $\longrightarrow$ PD3, if the road from PD3 to PS29 is blocked or closed due to emergency, then the distribution truck needs to detour PS29 back to PD3.

In the above example, the applications of several commonly used heuristic algorithms are compared to verify the effectiveness of the proposed IMOPSO algorithm. Table 12 compares ant colony algorithm (ACO) [38, 39], nondominated sorting genetic algorithm (NSGA-II) [40, 41], and IMOPSO algorithm. These three methods are used 20 times for computation of the example to compare the operation costs, numbers of distribution trucks, and the distribution time. Results show that, on average, IMOPSO obtained the lowest operating cost, and while the three algorithms obtained similar total usage of the distribution 


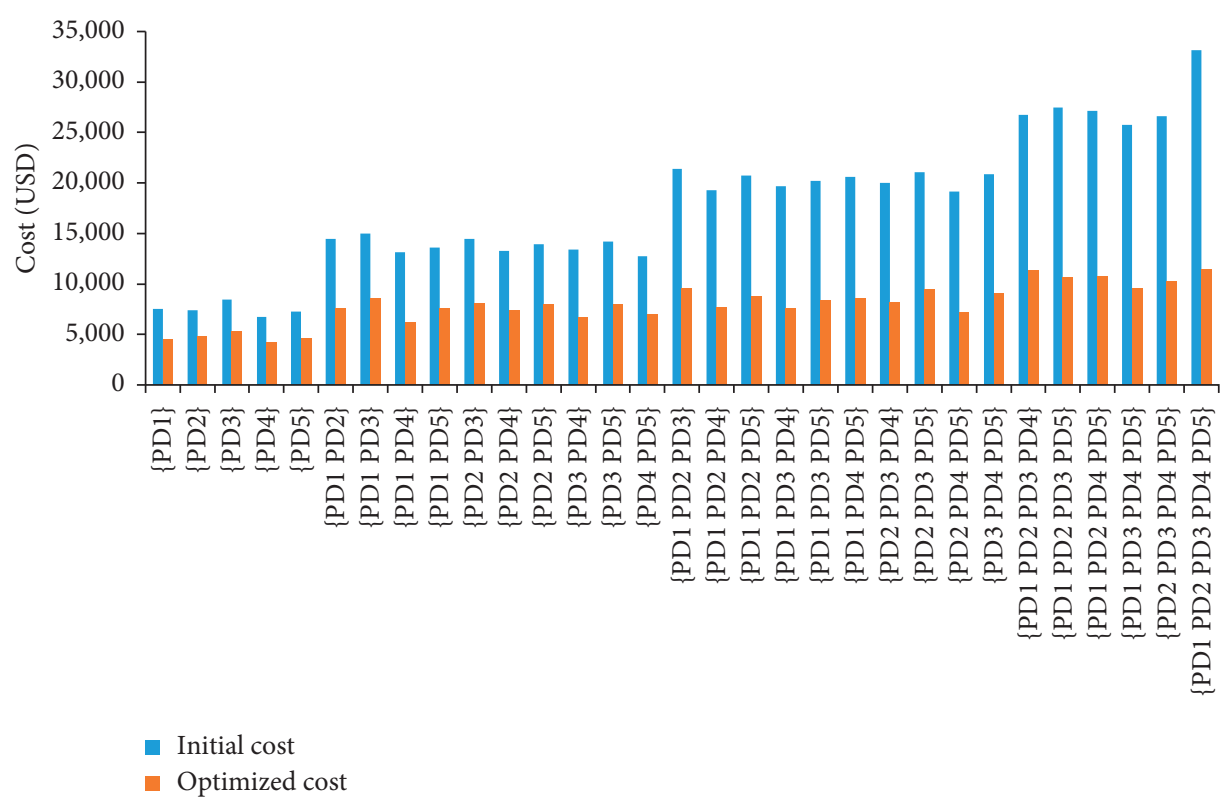

FIGURE 5: Comparison between initial and optimized networks cost solutions.

TABle 9: Comparison between initial delivery time and optimized delivery time (unit: minutes).

\begin{tabular}{|c|c|c|c|}
\hline Alliance & Initial delivery time & Optimized delivery time & Time saving \\
\hline$\{\mathrm{PD} 1\}$ & 1148 & 1148 & - \\
\hline$\{\mathrm{PD} 2\}$ & 1176 & 1176 & - \\
\hline$\{\mathrm{PD} 3\}$ & 1134 & 1134 & - \\
\hline$\{\mathrm{PD} 4\}$ & 952 & 952 & - \\
\hline$\{\mathrm{PD} 5\}$ & 1079 & 1079 & - \\
\hline$\{P D 1 P D 2\}$ & 2,324 & 1157 & 1167 \\
\hline$\{\mathrm{PD} 1 \mathrm{PD} 3\}$ & 2,282 & 1136 & 1146 \\
\hline$\{$ PD1 PD4 $\}$ & 2,100 & 1043 & 1057 \\
\hline$\{\mathrm{PD} 1 \mathrm{PD} 5\}$ & 2,227 & 1105 & 1122 \\
\hline$\{\mathrm{PD} 2 \mathrm{PD} 3\}$ & 2,310 & 1134 & 1176 \\
\hline$\{\mathrm{PD} 2 \mathrm{PD} 4\}$ & 2,128 & 1032 & 1096 \\
\hline$\{\mathrm{PD} 2 \mathrm{PD} 5\}$ & 2,255 & 1116 & 1139 \\
\hline$\{\mathrm{PD} 3 \mathrm{PD} 4\}$ & 2,086 & 1025 & 1061 \\
\hline$\{\mathrm{PD} 3 \mathrm{PD} 5\}$ & 2,213 & 1084 & 1129 \\
\hline$\{\mathrm{PD} 4 \mathrm{PD} 5\}$ & 2,031 & 1007 & 1024 \\
\hline$\{P D 1$ PD2 PD3 $\}$ & 3,472 & 1528 & 1,944 \\
\hline$\{\mathrm{PD} 1 \mathrm{PD} 2 \mathrm{PD} 4\}$ & 3,276 & 1473 & 1,803 \\
\hline$\{P D 1$ PD2 PD5 $\}$ & 3,403 & 1495 & 1,908 \\
\hline$\{\mathrm{PD} 1 \mathrm{PD} 3 \mathrm{PD} 4\}$ & 3,234 & 1466 & 1,768 \\
\hline$\{\mathrm{PD} 1 \mathrm{PD} 3 \mathrm{PD} 5\}$ & 3,361 & 1484 & 1,877 \\
\hline$\{\mathrm{PD} 1 \mathrm{PD} 4 \mathrm{PD} 5\}$ & 3,179 & 1452 & 1,727 \\
\hline$\{\mathrm{PD} 2 \mathrm{PD} 3 \mathrm{PD} 4\}$ & 3,262 & 1479 & 1,783 \\
\hline$\{\mathrm{PD} 2 \mathrm{PD} 3 \mathrm{PD} 5\}$ & 3,389 & 1495 & 1,894 \\
\hline$\{\mathrm{PD} 2 \mathrm{PD} 4 \mathrm{PD} 5\}$ & 3,207 & 1449 & 1,758 \\
\hline$\{\mathrm{PD} 3 \mathrm{PD} 4 \mathrm{PD} 5\}$ & 3,165 & 1446 & 1,719 \\
\hline$\{P D 1$ PD2 PD3 PD4 $\}$ & 4,410 & 2,113 & 2,297 \\
\hline$\{P D 1$ PD2 PD3 PD5 $\}$ & 4,551 & 2,167 & 2,384 \\
\hline$\{\mathrm{PD} 1 \mathrm{PD} 2 \mathrm{PD} 4 \mathrm{PD} 5\}$ & 4,355 & 2,108 & 2,247 \\
\hline$\{\mathrm{PD} 1 \mathrm{PD} 3 \mathrm{PD} 4 \mathrm{PD} 5\}$ & 4,313 & 2094 & 2,219 \\
\hline$\{\mathrm{PD} 2$ PD3 PD4 PD5 $\}$ & 4,341 & 2,010 & 2,331 \\
\hline$\{\mathrm{PD} 1 \mathrm{PD} 2 \mathrm{PD} 3 \mathrm{PD} 4 \mathrm{PD} 5\}$ & 5,503 & 2,389 & 3,114 \\
\hline
\end{tabular}

trucks, IMOPS showed less usage for single- and doublecompartment trucks, but more of three-compartment trucks. This result is consistent with the optimization goals, that is, to coordinate the service TW and petrol product demand of different PSs and strengthen the sharing of distribution trucks. From the point of distribution time, the 


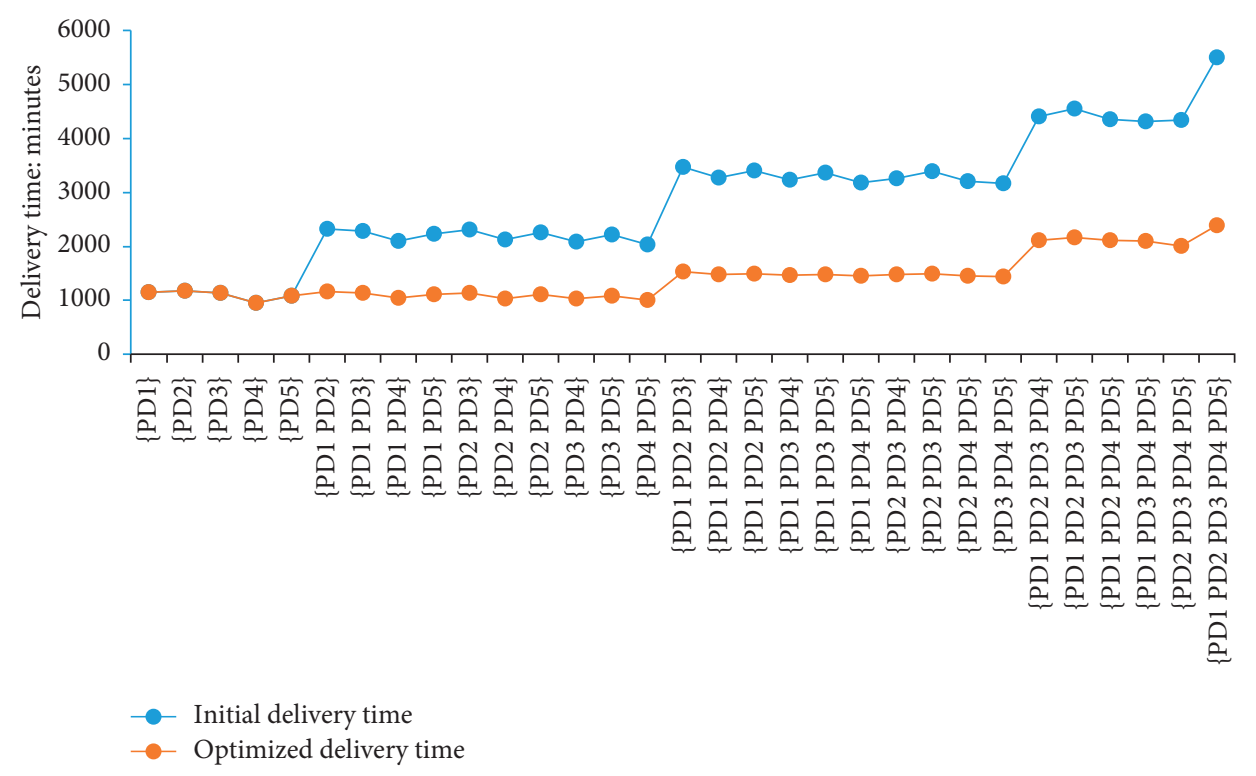

FIGURE 6: Comparison between initial and optimized network delivery time solutions.

TABle 10: Comparison of truck usage between initial and optimized networks (trucks/time).

\begin{tabular}{|c|c|c|c|c|c|c|}
\hline \multirow{2}{*}{ Alliance } & \multicolumn{3}{|c|}{ Initial truck usage } & \multicolumn{3}{|c|}{ Truck usage after optimization } \\
\hline & $k 1$ & $k 2$ & $k 3$ & $k 1$ & $k 2$ & $k 3$ \\
\hline$\{\mathrm{PD} 1\}$ & 6 & 8 & 6 & 6 & 8 & 6 \\
\hline$\{\mathrm{PD} 2\}$ & 6 & 8 & 5 & 6 & 8 & 5 \\
\hline$\{\mathrm{PD} 3\}$ & 6 & 7 & 7 & 6 & 7 & 7 \\
\hline$\{\mathrm{PD} 4\}$ & 5 & 6 & 4 & 5 & 6 & 4 \\
\hline$\{\mathrm{PD} 5\}$ & 5 & 7 & 5 & 5 & 7 & 5 \\
\hline$\{\mathrm{PD} 1 \mathrm{PD} 2\}$ & 12 & 16 & 11 & 2 & 8 & 15 \\
\hline$\{\mathrm{PD} 1 \mathrm{PD} 3\}$ & 12 & 15 & 13 & 2 & 8 & 16 \\
\hline$\{\mathrm{PD} 1 \mathrm{PD} 4\}$ & 11 & 14 & 10 & 3 & 7 & 12 \\
\hline$\{\mathrm{PD} 1 \mathrm{PD} 5\}$ & 11 & 15 & 11 & 2 & 8 & 14 \\
\hline$\{\mathrm{PD} 2 \mathrm{PD} 3\}$ & 12 & 15 & 12 & 2 & 8 & 15 \\
\hline$\{\mathrm{PD} 2 \mathrm{PD} 4\}$ & 10 & 14 & 9 & 3 & 7 & 11 \\
\hline$\{\mathrm{PD} 2 \mathrm{PD} 5\}$ & 11 & 15 & 10 & 2 & 8 & 13 \\
\hline$\{\mathrm{PD} 3 \mathrm{PD} 4\}$ & 11 & 13 & 11 & 3 & 6 & 12 \\
\hline$\{\mathrm{PD} 3 \mathrm{PD} 5\}$ & 11 & 14 & 12 & 2 & 8 & 15 \\
\hline$\{\mathrm{PD} 4 \mathrm{PD} 5\}$ & 10 & 13 & 9 & 3 & 7 & 12 \\
\hline$\{\mathrm{PD} 1 \mathrm{PD} 2 \mathrm{PD} 3\}$ & 18 & 23 & 18 & 3 & 12 & 24 \\
\hline$\{P D 1$ PD2 PD4 $\}$ & 16 & 22 & 15 & 2 & 11 & 21 \\
\hline$\{\mathrm{PD} 1 \mathrm{PD} 2 \mathrm{PD} 5\}$ & 17 & 23 & 16 & 3 & 12 & 22 \\
\hline$\{\mathrm{PD} 1 \mathrm{PD} 3 \mathrm{PD} 4\}$ & 17 & 21 & 17 & 2 & 11 & 23 \\
\hline$\{\mathrm{PD} 1 \mathrm{PD} 3 \mathrm{PD} 5\}$ & 17 & 22 & 18 & 4 & 12 & 24 \\
\hline$\{\mathrm{PD} 1 \mathrm{PD} 4 \mathrm{PD} 5\}$ & 16 & 21 & 15 & 3 & 11 & 21 \\
\hline$\{\mathrm{PD} 2$ PD3 PD4 $\}$ & 17 & 21 & 16 & 2 & 11 & 22 \\
\hline$\{\mathrm{PD} 2 \mathrm{PD} 3 \mathrm{PD} 5\}$ & 17 & 22 & 17 & 3 & 12 & 23 \\
\hline$\{\mathrm{PD} 2 \mathrm{PD} 4 \mathrm{PD} 5\}$ & 15 & 21 & 14 & 3 & 10 & 20 \\
\hline$\{\mathrm{PD} 3 \mathrm{PD} 4 \mathrm{PD} 5\}$ & 16 & 20 & 16 & 2 & 11 & 21 \\
\hline$\{P D 1$ PD2 PD3 PD4 $\}$ & 22 & 29 & 22 & 4 & 14 & 28 \\
\hline$\{P D 1$ PD2 PD3 PD5 $\}$ & 23 & 30 & 23 & 5 & 16 & 30 \\
\hline$\{\mathrm{PD} 1 \mathrm{PD} 2 \mathrm{PD} 4 \mathrm{PD} 5\}$ & 16 & 29 & 20 & 4 & 14 & 26 \\
\hline$\{\mathrm{PD} 1 \mathrm{PD} 3 \mathrm{PD} 4 \mathrm{PD} 5\}$ & 22 & 28 & 22 & 5 & 15 & 29 \\
\hline$\{\mathrm{PD} 2$ PD3 PD4 PD5 $\}$ & 21 & 28 & 21 & 5 & 14 & 28 \\
\hline$\{\mathrm{PD} 1 \mathrm{PD} 2 \mathrm{PD} 3 \mathrm{PD} 4 \mathrm{PD} 5\}$ & 27 & 36 & 27 & 6 & 17 & 35 \\
\hline
\end{tabular}




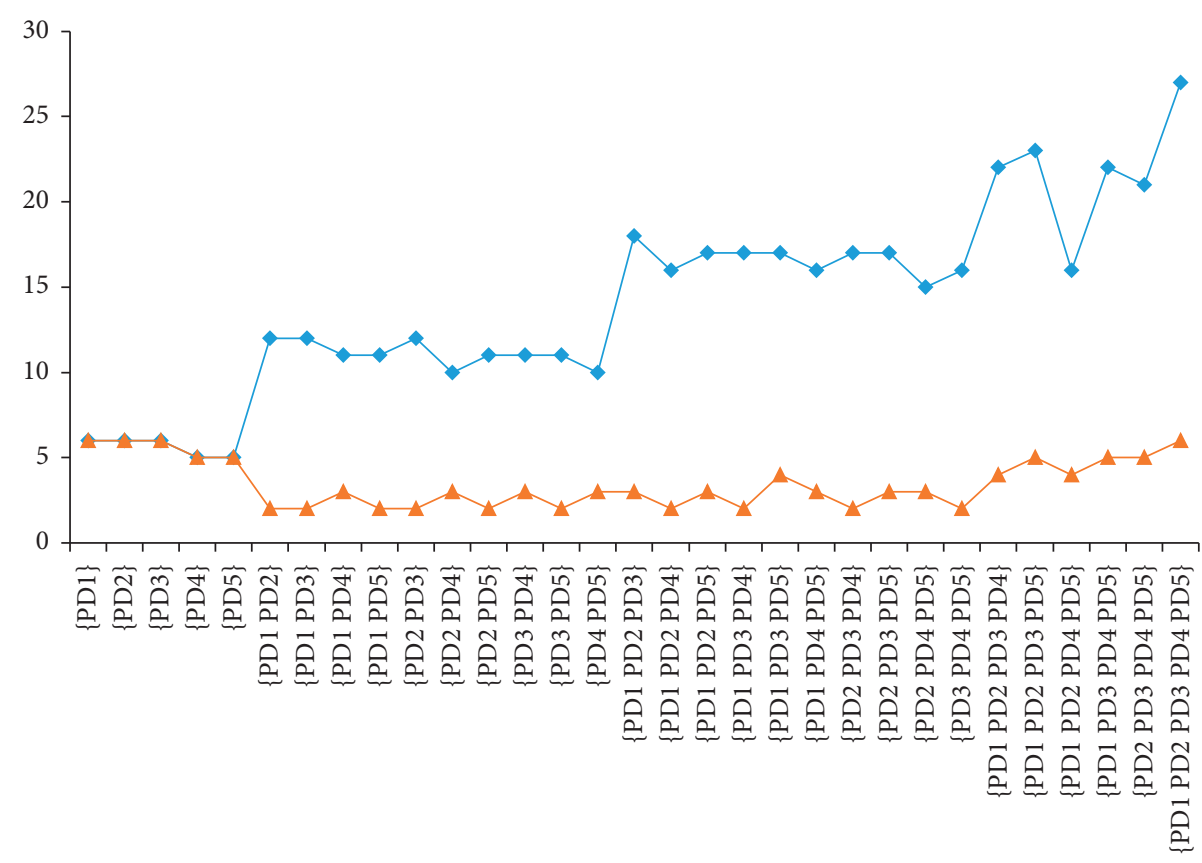

$\neg-$ The demand quantity of $k 1$ before cooperation (trucks/time)

$\_$The demand quantity of $k 1$ after cooperation (trucks/time)

FIgURE 7: Comparison between initial and optimized networks $k 1$ usage solutions.

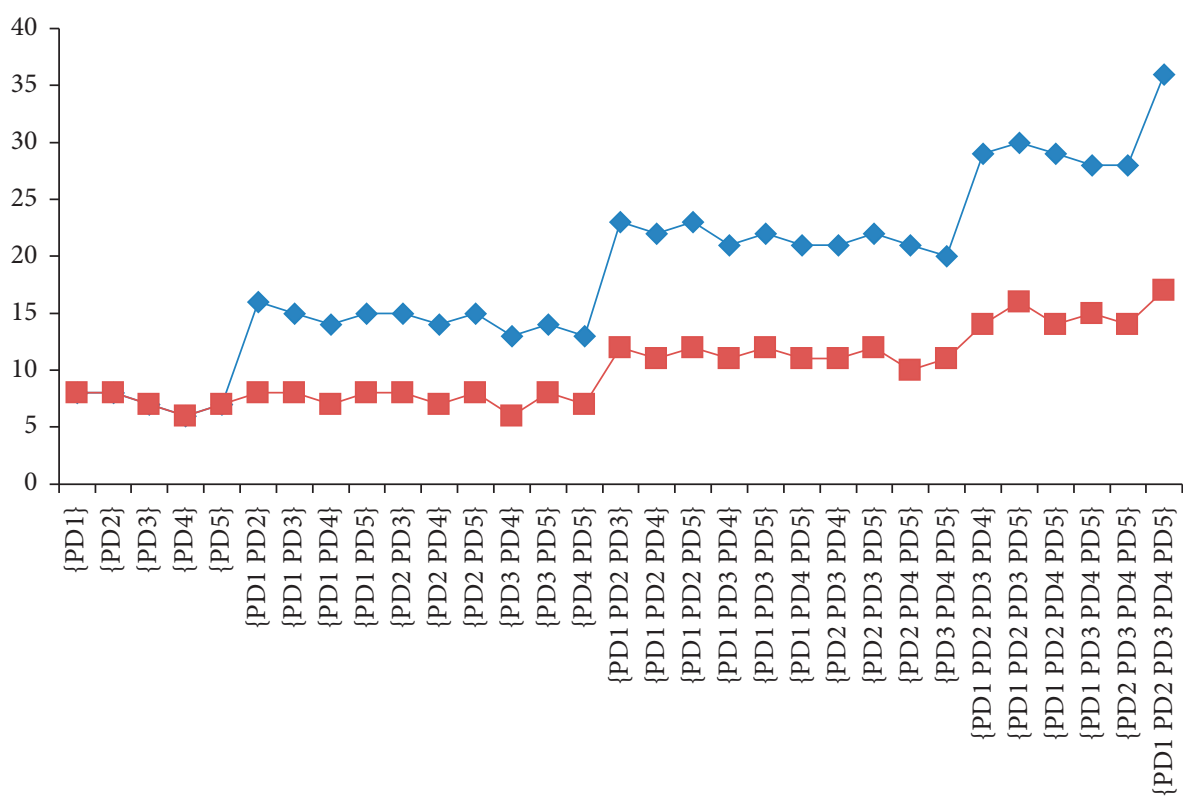

$\checkmark$ The demand quantity of $k 2$ before cooperation (trucks/time)

The demand quantity of $k 2$ after cooperation (trucks/time)

FIgURE 8: Comparison between initial and optimized networks $k 2$ usage solutions.

average distribution time calculated by ACO is the shortest, but only outperforms IMOPSO by 50 minutes, an acceptable slight disadvantage in operational management studies, especially in large distribution networks. Thus, IMOPSO can be considered effective and feasible in addressing the vehicle routing issues in multidepot cooperative emergency distribution of petrol products.
5.3. Implication. The optimization of coordinated PS replenishment vehicle route based on regional partitioning and reasonable resource sharing promotes the sustainable development of petrol distribution and emergency energy supply system. Through the optimization of CMPDVRPE, the petrol distribution service area is reasonably divided, long-distance and cross-traffic are reduced, and the 


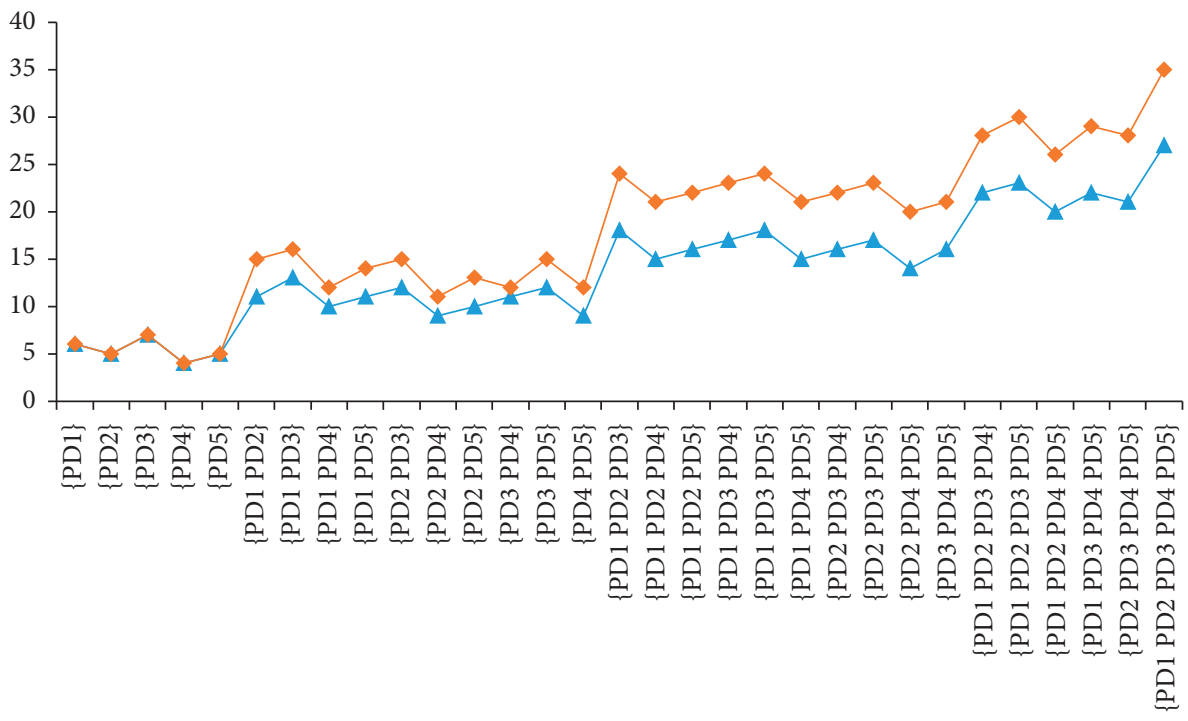

- The demand quantity of $k 3$ before cooperation (trucks/time)

FIgURE 9: Comparison between initial and optimized networks $k 3$ usage solutions.

TABLE 11: Distribution truck route arrangements of PD3 after optimization.

\begin{tabular}{|c|c|}
\hline $\mathrm{PD}$ & The distribution truck route network \\
\hline PD3 & 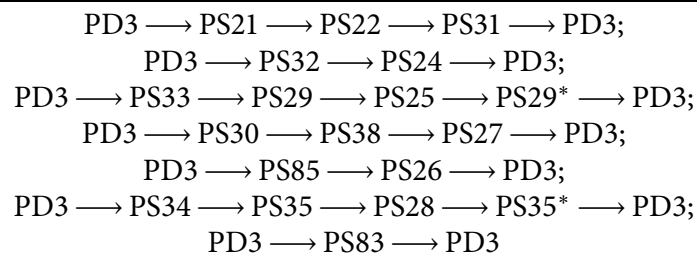 \\
\hline
\end{tabular}

*The petrol station passed by vehicles on a detour.

TABLE 12: Comparison of algorithm performances.

\begin{tabular}{|c|c|c|c|c|c|c|c|c|c|c|c|c|c|c|c|}
\hline \multirow{3}{*}{ Sequence } & \multicolumn{5}{|c|}{ IMOPSO } & \multicolumn{5}{|c|}{$\mathrm{ACO}$} & \multicolumn{5}{|c|}{ NSGA-II } \\
\hline & \multirow[t]{2}{*}{$\begin{array}{l}\text { Cost } \\
\text { (USD) }\end{array}$} & \multicolumn{3}{|c|}{$\begin{array}{c}\text { Trucks } \\
\text { (trucks/ } \\
\text { time) }\end{array}$} & \multirow[t]{2}{*}{$\begin{array}{l}\text { Distribution time } \\
\quad \text { (minutes) }\end{array}$} & \multirow[t]{2}{*}{$\begin{array}{l}\text { Cost } \\
\text { (USD) }\end{array}$} & \multicolumn{3}{|c|}{$\begin{array}{c}\text { Trucks } \\
\text { (trucks/ } \\
\text { time) }\end{array}$} & \multirow[t]{2}{*}{$\begin{array}{l}\text { Distribution time } \\
\text { (minutes) }\end{array}$} & \multirow[t]{2}{*}{$\begin{array}{l}\text { Cost } \\
\text { (USD) }\end{array}$} & \multicolumn{3}{|c|}{$\begin{array}{c}\text { Trucks } \\
\text { (trucks/ } \\
\text { time) }\end{array}$} & \multirow[t]{2}{*}{$\begin{array}{l}\text { Distribution time } \\
\text { (minutes) }\end{array}$} \\
\hline & & $k 1$ & $k 2$ & $k 3$ & & & $k 1$ & $k 2$ & $k 3$ & & & $k 1$ & $k 2$ & $k 3$ & \\
\hline 1 & 11,415 & 6 & 17 & 35 & 1980 & 13,248 & 8 & 20 & 33 & 2170 & 12,532 & 7 & 19 & 34 & 2060 \\
\hline 2 & 15,324 & 6 & 15 & 37 & 1550 & 15,023 & 8 & 18 & 31 & 1380 & 14,473 & 6 & 18 & 32 & 1610 \\
\hline 3 & 11,122 & 6 & 18 & 33 & 980 & 19,108 & 9 & 18 & 34 & 2220 & 12,914 & 7 & 17 & 32 & 2010 \\
\hline 4 & 11,184 & 6 & 16 & 35 & 1690 & 18,197 & 8 & 21 & 32 & 1450 & 11,403 & 8 & 19 & 33 & 1650 \\
\hline 5 & 10,707 & 6 & 16 & 36 & 1760 & 14,280 & 8 & 20 & 31 & 2130 & 14,627 & 8 & 17 & 34 & 2420 \\
\hline 6 & 12,750 & 6 & 17 & 36 & 1980 & 12,556 & 9 & 19 & 34 & 2230 & 18,158 & 7 & 18 & 33 & 1980 \\
\hline 7 & 12,566 & 8 & 15 & 32 & 2250 & 14,320 & 9 & 20 & 32 & 2180 & 16,232 & 8 & 17 & 33 & 2120 \\
\hline 8 & 17,355 & 5 & 15 & 38 & 1760 & 16,886 & 7 & 20 & 32 & 1430 & 14,654 & 6 & 18 & 33 & 2410 \\
\hline 9 & 12,229 & 6 & 18 & 35 & 1970 & 19,672 & 8 & 18 & 31 & 1300 & 12,434 & 6 & 18 & 34 & 1940 \\
\hline 10 & 13,338 & 8 & 16 & 34 & 1820 & 12,780 & 9 & 20 & 33 & 2410 & 12,516 & 6 & 19 & 33 & 1630 \\
\hline 11 & 14,820 & 8 & 15 & 34 & 1730 & 16,830 & 7 & 20 & 31 & 930 & 12,721 & 8 & 17 & 34 & 2310 \\
\hline 12 & 14,842 & 8 & 17 & 32 & 2230 & 14,019 & 8 & 19 & 33 & 1690 & 17,029 & 7 & 17 & 34 & 1970 \\
\hline 13 & 15,520 & 7 & 15 & 34 & 2270 & 14,210 & 9 & 19 & 34 & 2190 & 14,591 & 7 & 17 & 33 & 2090 \\
\hline 14 & 14,670 & 5 & 18 & 33 & 1900 & 18,683 & 9 & 21 & 34 & 860 & 13,717 & 8 & 17 & 32 & 900 \\
\hline 15 & 16,051 & 6 & 17 & 34 & 1950 & 17,252 & 8 & 19 & 32 & 2310 & 12,716 & 8 & 19 & 32 & 2010 \\
\hline 16 & 15,862 & 7 & 18 & 36 & 860 & 17,760 & 8 & 19 & 32 & 2340 & 12,336 & 7 & 17 & 34 & 1680 \\
\hline 17 & 12,312 & 6 & 17 & 36 & 1830 & 12,856 & 7 & 18 & 34 & 1570 & 15,641 & 8 & 18 & 34 & 1980 \\
\hline 18 & 12,322 & 8 & 16 & 37 & 2060 & 17,903 & 8 & 19 & 34 & 880 & 17,947 & 7 & 19 & 33 & 2410 \\
\hline 19 & 13,454 & 8 & 16 & 33 & 1610 & 15,404 & 7 & 20 & 31 & 2610 & 18,621 & 6 & 17 & 33 & 2530 \\
\hline 20 & 13,254 & 6 & 15 & 33 & 2110 & 14,422 & 8 & 20 & 31 & 950 & 15,297 & 8 & 17 & 32 & 2420 \\
\hline Average & 13,555 & 7 & 16 & 35 & 1810 & 15,770 & 8 & 19 & 32 & 1760 & 14,528 & 7 & 18 & 33 & 2010 \\
\hline
\end{tabular}


distribution time is shortened. Thus, costs are minimized and additional benefits are provided to each PD. Effective vehicle routing arrangement and sharing matching strategy between vehicles and PSs are the important characteristics of this network. These improvements greatly enhance energy and social resources, cost savings, and emergency response capabilities for PD operators and transportation management.

Cooperation among logistics facilities plays an important role in optimizing the distribution in cases of emergency [42-44]. Further integration of transportation resource sharing and optimization of vehicle routing can further save on costs. In addition, traffic management policies that encourage joint distribution are also a sign of political will to achieve sustainable development in administrative areas $[31,32]$. As one of the major development factors, petrol distribution activities can be further organized under the coordination of vehicle routes, reducing the number of petrol distribution trucks. Therefore, encouraging the formation of grand coalitions is a relevant method that can benefit not only PDs, but also society as a whole.

\section{Conclusions}

This study proposes an effective method to solve the CMPDVRPE optimization, which improves the cooperation of PDs and the efficient distribution vehicle routing optimization in emergencies. Through the cooperation between PDs, regional petrol joint distribution, optimization of distribution, and resource sharing can be formed. In the optimization, PS clustering mechanism, road blocking, and TS mechanism are considered. Comparison of the data before and after the cooperation shows that the total operating cost, total delivery time, and the total number of delivery vehicles are significantly decreased.

The optimization model considers customer clustering, multicompartment TS, roadblocks, and TWC, thereby reducing the overall transport distance and the number of trucks used. Taking the regional petrol distribution network in Chongqing as an example, the application of the model and method is evaluated. A heuristic algorithm IMOPSO is proposed, and a case study of different scales of petrol distribution networks was carried out. The operating cost, delivery time, and the number of different types of trucks are compared before and after optimization.

In summary, the optimization of petrol emergency distribution vehicle routing is consistent with reality. The proposed optimization method is superior to the existing research in this field. On the basis of the analysis, the following conclusions are drawn. (1) Through customer clustering, multicompartment TS, vehicle routing optimization, and TWC, the regional petrol distribution network can considerably reduce the delivery time, number of distribution trucks required, and the total operating cost of the petrol distribution network. (2) Optimizing the PSs for each PD and sharing trucks when the TW demand allows can reduce traffic pressure in urban areas and its negative impact on the energy supply system and contribute to the sustainable development of urban traffic. (3) Timely and efficient supply of petrol is guaranteed through optimization of vehicle routing of petrol emergency distribution.

The results of this study point to interesting research directions for the future. The following views can be considered. (1) This study only examines the cooperation between PD and PS in the secondary distribution of petrol. Thus, the cooperation between the two sides can extend to the transport energy supply chain. (2) Consistent with most existing joint distribution literature, this study assumes a constant transportation speed of petrol distribution trucks. Future research can consider real-time urban traffic speed analysis to obtain more realistic results. (3) From the perspective of vehicle-road interaction, the influence of road geometry on the selection of multicompartment vehicle types can be considered in the future. (4) In the future, a dynamic CMPDVRPE model can be established by considering the spatiotemporal change of roadblocks or congestion.

\section{Data Availability}

The service time window and demand quantity data used to support the findings of this study are available from the corresponding companies and administrative departments.

\section{Conflicts of Interest}

The authors declare that they have no conflicts of interest.

\section{Acknowledgments}

This research was supported by the Social Science Foundation of Chongqing of China (Grant nos. 2020BS62, 2020TBWT-ZD02, 2019YBGL049, and 2020YBGL85), the Special Project of Technology Foresight and System Innovation of Chongqing of China (Grant no. cstc2020jsyjzdxwtB0003), the National Natural Science Foundation of China (Grant no. 71871035), Humanity and Social Science Foundation of Ministry of Education of China (Grant nos. 18YJC630189 and 17YJA630079), and Humanity and Social Sciences Research Project of Chongqing Education Commission (Grant no. 20SKGH232).

\section{References}

[1] F. Cornillier, F. Boctor, and J. Renaud, "Heuristics for the multi-depot petrol station replenishment problem with time windows," European Journal of Operational Research, vol. 220, no. 2, pp. 361-369, 2012.

[2] L. Bruggen, R. Gruson, and M. Salomon, "Reconsidering the distribution structure of gasoline products for a large oil company," European Journal of Operational Research, vol. 81, no. 3, pp. 460-473, 1995.

[3] Y. Wang, X. Ma, Z. Li, Y. Liu, M. Xu, and Y. Wang, "Profit distribution in collaborative multiple centers vehicle routing problem," Journal of Cleaner Production, vol. 144, pp. 203219, 2017.

[4] Y. Wang, Y. Yuan, X. Guan, M. Xu, and Y. Liu, “"Collaborative two-echelon multicenter vehicle routing optimization based on state-space-time network representation," Journal of Cleaner Production, vol. 258, pp. 1-26, 2020. 
[5] F. Cornillier, F. F. Boctor, G. Laporte, and J. Renaud, "A heuristic for the multi-period petrol station replenishment problem," European Journal of Operational Research, vol. 191, no. 2, pp. 295-305, 2008.

[6] F. Cornillier, G. Laporte, F. F. Boctor, and J. Renaud, "The petrol station replenishment problem with time windows," Computers \& Operations Research, vol. 36, no. 3, pp. 919-935, 2009.

[7] F. F. Boctor, J. Renaud, and F. Cornillier, "Trip packing in petrol stations replenishment," Omega, vol. 39, no. 1, pp. 86-98, 2011.

[8] D. Popović, M. Vidović, and G. Radivojević, "Variable neighborhood search heuristic for the inventory routing problem in fuel delivery," Expert Systems with Applications, vol. 39, no. 18, pp. 13390-13398, 2012.

[9] M. Vidović, D. Popović, and B. Ratković, "Mixed integer and heuristics model for the inventory routing problem in fuel delivery," International Journal of Production Economics, vol. 147, pp. 593-604, 2014.

[10] B. Wang, Y. Liang, M. Yuan, H. Zhang, and Q. Liao, "A metaheuristic method for the multireturn-to-depot petrol truck routing problem with time windows," Petroleum Science, vol. 16, no. 3, pp. 701-712, 2019.

[11] L. Wang, J. Kinable, and T. Woensel, “The fuel replenishment problem: a split delivery multi-compartment vehicle routing problem with multiple trips," Computers and Operations Research, vol. 118, pp. 1-16, 2020.

[12] S.-H. Huang, "Solving the multi-compartment capacitated location routing problem with pickup-delivery routes and stochastic demands," Computers \& Industrial Engineering, vol. 87, pp. 104-113, 2015.

[13] U. Derigs, J. Gottlieb, J. Kalkoff, M. Piesche, F. Rothlauf, and U. Vogel, "Vehicle routing with compartments: applications, modelling and heuristics," OR Spectrum, vol. 33, no. 4, pp. 885-914, 2011.

[14] R. Lahyani, L. C. Coelho, M. Khemakhem, G. Laporte, and F. Semet, "A multi-compartment vehicle routing problem arising in the collection of olive oil in Tunisia," Omega, vol. 51, pp. 1-10, 2015.

[15] L. C. Coelho and G. Laporte, "Classification, models and exact algorithms for multi-compartment delivery problems," European Journal of Operational Research, vol. 242, no. 3, pp. 854-864, 2015.

[16] M. Ostermeier and A. Hübner, "Vehicle selection for a multicompartment vehicle routing problem," European Journal of Operational Research, vol. 269, no. 2, pp. 682-694, 2018.

[17] M. Qi, W.-H. Lin, N. Li, and L. Miao, "A spatiotemporal partitioning approach for large-scale vehicle routing problems with time windows," Transportation Research Part E: Logistics and Transportation Review, vol. 48, no. 1, pp. 248-257, 2012.

[18] F. Moreira, D. Pereira da Silva, L. Guimarães, P. Amorim, and B. Almada-Lobo, "The time window assignment vehicle routing problem with product dependent deliveries," Transportation Research Part E: Logistics and Transportation Review, vol. 116, pp. 163-183, 2018.

[19] S. Martins, M. Ostermeier, P. Amorim, A. Hübner, and B. Almada-Lobo, "Product-oriented time window assignment for a multi-compartment vehicle routing problem," European Journal of Operational Research, vol. 276, no. 3, pp. 893-909, 2019.

[20] R. Eshtehadi, E. Demir, and Y. Huang, "Solving the vehicle routing problem with multi-compartment vehicles for city logistics," Computers and Operations Research, vol. 115, pp. 1-16, 2020.
[21] X. Wang, H. Zhan, and J. Zhang, "Research of oil product secondary distribution optimization based on collaborative distribution," Procedia Computer Science, vol. 60, pp. 13671376, 2015.

[22] Y. Wang, Y. Yuan, K. Assogba et al., "Design and profit allocation in two-echelon heterogeneous cooperative logistics network optimization," Journal of Advanced Transportation, vol. 2018, Article ID 4607493, 20 pages, 2018.

[23] Y. Wang, S. Zhang, X. Guan et al., "Collaborative multi-depot logistics network design with time window assignment," Expert Systems with Applications, vol. 140, pp. 1-24, 2020.

[24] J.-B. Sheu, "An emergency logistics distribution approach for quick response to urgent relief demand in disasters," Transportation Research Part E: Logistics and Transportation Review, vol. 43, no. 6, pp. 687-709, 2007.

[25] Q. Zhang and S. Xiong, "Routing optimization of emergency grain distribution vehicles using the immune ant colony optimization algorithm," Applied Soft Computing, vol. 71, pp. 917-925, 2018.

[26] D. Huizing, G. Schäfer, R. D. van der Mei, and S. Bhulai, "The median routing problem for simultaneous planning of emergency response and non-emergency jobs," European Journal of Operational Research, vol. 285, no. 2, pp. 712-727, 2020.

[27] R. J. Kuo, F. E. Zulvia, and K. Suryadi, "Hybrid particle swarm optimization with genetic algorithm for solving capacitated vehicle routing problem with fuzzy demand-a case study on garbage collection system," Applied Mathematics and Computation, vol. 219, no. 5, pp. 2574-2588, 2012.

[28] Y. Wang, X. Ma, M. Xu, Y. Liu, and Y. Wang, “Two-echelon logistics distribution region partitioning problem based on a hybrid particle swarm optimization-genetic algorithm," $E x$ pert Systems with Applications, vol. 42, no. 12, pp. 5019-5031, 2015.

[29] H. Zhou, M. Song, and W. Pedrycz, "A comparative study of improved GA and PSO in solving multiple traveling salesmen problem," Applied Soft Computing, vol. 64, pp. 564-580, 2018.

[30] K. Govindan, A. Jafarian, R. Khodaverdi, and K. Devika, "Two-echelon multiple-vehicle location-routing problem with time windows for optimization of sustainable supply chain network of perishable food," International Journal of Production Economics, vol. 152, pp. 9-28, 2014.

[31] Y. Wang, S. Peng, X. Zhou, M. Mahmoudi, and L. Zhen, "Green logistics location-routing problem with eco-packages," Transportation Research Part E: Logistics and Transportation Review, vol. 143, pp. 1-33, 2020.

[32] C. Xu, P. Liu, W. Wang, and Z. Li, "Identification of freeway crash-prone traffic conditions for traffic flow at different levels of service," Transportation Research Part A: Policy and Practice, vol. 69, pp. 58-70, 2014.

[33] G. Xu, M. Xu, Y. Wang, Y. Liu, and Q. lv, "Collaborative multidepot petrol station replenishment problem with multicompartments and time window assignment," Journal of Advanced Transportation, vol. 2020, Article ID 8843397, 22 pages, 2020.

[34] J. Kennedy and R. Eberhart, "Particle swarm optimization," in Proceedings of the International Conference on Neural Networks (ICNN'95), vol. 4, pp. 1942-1948, Perth, WA, Australia, November 1995.

[35] C. Coello and M. Lechuga, "MOPSO: a proposal for multiple objective particle swarm optimization," in Proceedings of the 2002 Congress on Evolutionary Computation, pp. 1051-1056, Honolulu, HI, USA, May 2002.

[36] K. Deb, S. Agrawal, A. Pratap, and T. Meyarivan, "A fast elitist non-dominated sorting genetic algorithm for multi-objective 
optimization: NSGA-II," in Proceeding of Parallel Problem Solving from Nature VI Conference, pp. 849-858, Paris, France, September 2000.

[37] Y. Shi and R. Eberhart, "A modified particle swarm optimizer," in Proceedings of the IEEE International Conference on Evolutionary Computation, pp. 69-73, Piscataway, NJ, USA, May 1998.

[38] Y.-H. Huang, C. A. Blazquez, S.-H. Huang, G. Paredes-Belmar, and G. Latorre-Nuñez, "Solving the feeder vehicle routing problem using ant colony optimization," Computers \& Industrial Engineering, vol. 127, pp. 520-535, 2019.

[39] Y. Li, H. Soleimani, and M. Zohal, "An improved ant colony optimization algorithm for the multi-depot green vehicle routing problem with multiple objectives," Journal of Cleaner Production, vol. 227, pp. 1161-1172, 2019.

[40] A. Martínez-Puras and J. Pacheco, "MOAMP-Tabu search and NSGA-II for a real bi-objective scheduling-routing problem," Knowledge-Based Systems, vol. 112, pp. 92-104, 2016.

[41] A. Rauniyar, R. Nath, and P. K. Muhuri, "Multi-factorial evolutionary algorithm based novel solution approach for multi-objective pollution-routing problem," Computers \& Industrial Engineering, vol. 130, pp. 757-771, 2019.

[42] J.-B. Sheu and C. Pan, "A method for designing centralized emergency supply network to respond to large-scale natural disasters," Transportation Research Part B: Methodological, vol. 67, pp. 284-305, 2014.

[43] Y. Huang, "Modeling and simulation method of the emergency response systems based on OODA," Knowledge-Based Systems, vol. 89, pp. 527-540, 2015.

[44] Y. Liu, Y. Wang, M. Xu, and G. Xu, "Emergency alternative evaluation using extended trapezoidal intuitionistic fuzzy thermodynamic approach with prospect theory," International Journal of Fuzzy Systems, vol. 21, no. 6, pp. 1801-1817, 2019. 